\title{
LOS ÚLTIMOS AVANCES EN LA CODIFICACIÓN DEL DERECHO CIVIL CHINO*
}

\author{
THE LATEST DEVELOPMENTS IN THE CODIFICATION OF \\ CHINESE CIVIL LAW
}

\section{LIHONG ZHANG**}

SUMARIO: I. Introducción: breve historia y situación actual del Derecho Civil chino: A. Los Principios Generales de Derecho Civil (PGDC); B. Las leyes especiales, civiles y comerciales, y las disposiciones de Derecho Público (fundamentalmente administrativas) reguladoras de relaciones civiles o comerciales; C. Las interpretaciones judiciales. II. Los últimos avances en la codificación del Derecho Civil chino: A. Debates sobre la estructura de un futuro Código Civil de China; B. Proyecto de Código Civil de 2002; C. Debate sobre el Proyecto de Código Civil de 2002: ideas de anticodificación y decodificación en China; D. Ley sobre Derechos Reales de 2007; E. Crítica académica a la Ley sobre Derechos Reales de 2007: 1. Sobre la protección de la propiedad estatal, 2. Sobre la posibilidad de comercializar el derecho de uso de tierras rurales para la habitación, 3. Sobre la usucapión [prescripción adquisitiva extraordinaria], 4. Sobre cómo definir el interés público, 5. Sobre el carácter gratuito de la restitución de una cosa perdida, 6. Sobre el concepto de derecho real y la naturaleza de la Ley sobre Derechos Reales; F. Los últimos avances en el Proyecto de Derecho de Daños de China; G. La última versión del Proyecto de Derecho de Daños: contenido y características; H. Los debates actuales sobre Derecho de Daños: 1. Sobre el nombre y la naturaleza del Derecho de Daños, 2. Sobre cómo establecer cláusulas generales de la Ley de Daños, 3. Sobre los daños especiales y sus tipos: a. El daño ocasionado por el Estado, b. El daño proveniente del abuso de confianza, c. El daño resultante de accidentes laborales, d. El daño por interferencia en futuras relaciones contractuales, e. El daño ocasionado por el profesional, 4. Sobre la indemnización por daños, 5. Sobre los modos de extinción de la responsabilidad por daños. III. Conclusión.

Palabras clave: derecho chino, derecho civil, derechos reales, derecho de daños.

ABSTRACT: I. Introduction: brief history and current situation of chinese civil law; A. The GPCL; B. Special Civil and Commercial Laws, and the Provisions Stipulated by

\footnotetext{
* The Latest Developments in the Codification of Chinese Civil Law. Trad. dirigida por el Dr. PatricioIgnacio Carvajal, Profesor de Derecho Romano de la Pontificia Universidad Católica de Chile, y realizada en conjunto con el ayudante, Sr. Crescente Molina, y los alumnos, Srta. Marcela Prieto, Srta. Camila Riquelme, Sr. Felipe Jiménez y Sr. Nicolás Retamales. Agradecemos especialmente a la Sra. Sandra Chauvin de la Tulane Law Review por autorizarnos para efectuar y reproducir la traducción, y por razones de esta es que las notas al pie conservan el formato original de su publicación.

** Profesor de Derecho en la Universidad de Ciencia Política y Derecho de China Oriental (UCPDCO, Shangai, China) y Director del Centro de Derecho Romano y Derecho Europeo de la UCPDCO. Doctor en Derecho Romano y Derecho Civil por la Universidad de Roma "La Sapienza" (Italia). E-mail: lihong111@gmail.com
} 
Public Laws (Mainly Administrative Laws), Governing Civil or Commercial Relationships; C. Judicial Interpretations. II. The latest developments in the codification of chinese civil law; A. Debates on the Structure of China's Future Civil Code; B. 2002 Civil Code Draft; C. Debate on the 2002 Civil Code Draft: Anticodification and Decodification Ideas in China; D. 2007 Real Right Law; E. Academic Criticism of the 2007 Real Right Law, 1. On the Protection of State Property, 2. On the Possibility of Marketing the Right To Use Rural Land for Housing, 3. On the Usucapion, 4. On How To Define the Public Interest, 5. On the Gratuitous Character of the Return of a Lost Thing, 6. On the Concept of Real Right and the Nature of Real Right Law; F. The Latest Developments in the Drafting of China's Tort Law; G. The Latest Version of the Tort Law Draft: Content and Characteristics; H. The Current Debates on Tort Law, 1. On the Name and the Nature of Tort Law, 2. On How To Provide the General Clauses of Tort Law, 3. On the Special Torts and Their Types, a. Tort Committed by the State, b. Tort Resulting from Accomplishment, of Friendship, c. Tort Resulting from a Labor Accidents, d. Tort of Interference with Prospective Contractual Relations, e. Tort Committed by the Professional, 4. On Compensation for Damages, 5. On the Methods of Discharge of Tort Liability; III. Conclusion.

Key words: chinese law, civil law, property law, tort law.

\section{INTRODUCCIÓN: BREVE HISTORIA Y SITUACIÓN ACTUAL DEL DERECHO CIVIL CHINO}

El Derecho Civil tradicional chino se mantuvo bajo la forma de derecho consuetudinario hasta la promulgación del Código Civil de la República de China en 1929. Este Código fue modelado, esencialmente, sobre la base del Bürgerliches Gesetzbuch (BGB) (Código Civil alemán) y el Código Suizo de las Obligaciones de 1911¹. Después de la fundación de la República Popular de China (RPC), en 1949, este primer Código Civil en la historia china fue abolido en la zona continental; de modo que solo se mantuvo en vigencia en Taiwán ${ }^{2}$.

\footnotetext{
${ }^{1}$ Vid. The Civil Code Of The Republic Of China (Yukon Chang, Ching-Lin Hsia \& James L.E. Chow trans., University Publications of America, Inc., 1976) (1930); R.C.W. Sheng, Civil Code of the Republic of China, 4 CHINA L. REV. 69 (Oceana Pubs. 1975) (1929); vid., también, The Swiss Federal Code Of Obligations (Simon L. Goren trans., 1987) (1911); The German Civil Code (Simon L. Goren trans., 1989). 2 Para un análisis detallado sobre la historia de la codificación del Derecho Civil chino, vid. Jerome Alan Cohen, Contemporary Chinese Law: Research Problems and Perspectives (1970); Ling Bing, Civil Law, en Introduction to Chinese Law 170 (Wang Chengguang \& Zhang Xiaochun eds., 1997); Civil Law in Qing and Republican China (Kathryn Bernhardt \& Philip C.C. Huang eds., 1994); René David \& Camille Jauffretspinosi, Les Grands Systèmes de Droit Contemporains (8th ed. 1982); Edward J. Epstein, Codification of Civil Law in the People's Republic of China: Form and Substance in the Reception of Concepts and Elements of Western Private Law, 32 Univ. Brit. Colum. L. Rev. 153, 162 (1998). Vid, también, Liang Zhiping, Law, Politics and Social Change: Codification in China Since 1902, en Codici: Una Riflessione Di Fine Millennio 407 (Paolo Cappellini \& Bernardo Sordi eds., 2002); Wang Liming, Zhong Guo Min Fa Dian Zhi Ding De Hui Gu Yu Zhan Wang [Revisión y Perspectivas de la Codificación del Código Civil chino], 2008 Fa Xue Lun Tan [Foro Legal] número 3, en 5; Wang Zhenmin, The Roman Law Tradition and Its Future Development in China, 1 Frontiers. China 72 (2006); Zhang Lihong, The Codification of Civil Law in China: History, Current Situation and Prospective, 7/8 Studium Iuris 896-908 (2004).
} 
Antes de su apertura al mundo, en el año 1979, China intentó nuevamente elaborar un Código Civil en dos oportunidades: desde 1954 y desde $1962^{3}$. Sin embargo, no pudo codificar su Derecho Civil debido tanto al fortalecimiento de la escuela de pensamiento llamada del "nihilismo legal" como al resultado de algunos movimientos políticos (los llamados “Contra el Derecho" y "Tres Saltos", de 1956 a 1960; así como la Revolución Cultural, de 1965 a 1975). Pero poco después de la visita del líder político Deng Xiaoping a los Estados Unidos, en 1978, China comenzó su reforma legislativa -junto con su bien conocida reforma económica-, por medio de la promulgación de algunas leyes civiles y comerciales especiales ${ }^{4}$. Así, en 1982, después del éxito de la reforma económica, el legislador volvió a planificar la elaboración de un Código Civil. En esa época la doctrina rusa dominaba todo el Derecho Civil chino. Y, por ello, la teoría soviética del Derecho Económico provocó un fuerte debate sobre los diferentes ámbitos de acción del Derecho Civil y del Económico ${ }^{5}$. De modo que, dado tal debate y la política pragmática de los políticos chinos, el Poder Legislativo desistió de la codificación del Derecho Civil y solo promulgó, en 1986, los Principios Generales de Derecho Civil (PGDC). Aunque no fueron un Código Civil, los PGDC, con sus nueve partes y 156 artículos, estatuyeron los más importantes principios jurídicos e instituciones. Esto se verificó gracias a la adopción de muchos conceptos jurídicos e instituciones del

\footnotetext{
${ }^{3}$ En la RPC, el primer intento de elaboración de un Código Civil comenzó en 1954 y terminó en 1956 con un texto de trabajo modelado sobre la base del Código Civil ruso, el cual distribuía 500 artículos en cuatro partes: (1) Disposiciones Generales; (2) Propiedad; (3) Obligaciones; y (4) Sucesiones. En 1962, la RPC por segunda vez inició la elaboración de un Código Civil. Este proyecto fue concluido en 1964, y estuvo compuesto por tres partes, con 252 artículos: (1) Disposiciones Generales; (2) Propiedad; y (3) Transmisión de las Propiedades. En el Proyecto de 1964, el legislador chino no tomó en cuenta ninguna experiencia extranjera de codificación. Como resultado, el Proyecto prácticamente estuvo desprovisto de disposiciones jurídicas y, en su lugar, fue integrado por eslóganes políticos.

${ }^{4}$ Ley China sobre Foreign Equity Joint Ventures (promulgada como modificación por el Congreso Nacional Popular, 15 marzo 2001, vigente 1 julio 1979), LAWINFOCHINA (última visita el 30 de enero de 2009); Ley de Matrimonio (promulgada como modificación por el Comité Permanente del Congreso Popular Nacional, 28 abril 2001, vigente 1 enero 1980) LAWINFOCHINA (última visita el 30 de enero de 2009); Ley Económica de Contratación (promulgada por el Comité Permanente del Congreso Popular Nacional, 13 diciembre 1981, vigente 1 julio 1982) LAWINFOCHINA (última visita el 30 de enero de 2009); Ley de Marcas (promulgada por el Comité Permanente del Congreso Popular Nacional, 23 agosto 1982, vigente 3 marzo 1983) LAWINFOCHINA (última visita el 30 de enero de 2009); Ley de Patentes (promulgada por el Comité Permanente del Congreso Popular Nacional, 12 marzo 1984, vigente 1 abril 1985) LAWINFOCHINA (última visita el 30 de enero de 2009); Ley de Sucesiones (promulgada por el Congreso Popular nacional, 10 abril 1985, vigente 1 octubre 1985) LAWINFOCHINA (última visita el 30 de enero de 2009); Ley Económica de Contratación relativa a Intereses Extranjeros (promulgada por el Comité Permanente del Congreso Popular Nacional, 21 marzo 1985, vigente 1 julio 1985) LAWINFOCHINA (última visita el 30 de enero de 2009).

${ }^{5}$ Bajo la fuerte influencia de la famosa Teoría del Derecho Económico de Pashukanis, de acuerdo a la cual todas las relaciones económicas en un país socialista deben estar regidas por el Derecho Económico, en los comienzos de 1980, la Ley de Contratación de China fue denominada "Ley Económica", y se dividió en dos partes: Ley Económica de Contratación, de 1981, y Ley Económica de Contratación relativa a Intereses Extranjeros, de 1985. En oposición a esta Teoría del Derecho Económico, la mayoría de los profesores de Derecho Civil alegaron que las relaciones económicas entre sujetos de igual condición debían ser reguladas por el Derecho Civil; calificando las leyes económicas como el derecho que rige solo el manejo económico del Gobierno y las relaciones económicas entre el Estado y las empresas, vid. Epstein, supra nota 2, en 165.
} 
Derecho Romano y del Derecho continental: como la persona jurídica, el Rechtsgeschäft (negocio jurídico), la limitación de acciones, la responsabilidad civil y otros ${ }^{6}$. Además, en China, tal como en Italia, el Derecho Civil y el Derecho Comercial fueron unificados legislativamente; $y$, en consecuencia, los PGDC también son directamente aplicables en el campo mercantil, excepto si existe una ley especial de esta área.

En términos de derecho positivo, aparte del derecho consuetudinario, las actuales normas de Derecho Civil (y Comercial) en China se componen esencialmente de tres partes: los PGDC, las leyes especiales, civiles y comerciales, y las interpretaciones judiciales.

\section{A. LOs PGDC}

Los PGDC son el origen de la legislación civil china y, a la vez, la única norma civil fundamental del Congreso Popular Nacional ${ }^{7}$. Son el estatuto supremo del Derecho Civil y, por tanto, cualquier disposición especial de Derecho Civil o Comercial que pugne con los PGDC es inválida. En suma, los PGDC constituyen el marco de interpretación de todo el Derecho Civil de China.

\section{B. LAS LEYES ESPECIALES, CIVILES Y COMERCIALES, Y LAS DiSPOSICIONES DE DERECHO PÚblico (Fundamentalmente AdMinistrativas) REGULADORAS DE RELACIONES CIVILES O COMERCIALES}

Después de la promulgación de los PGDC, en 1986, y en particular después de que China decidiera abandonar la economía planificada y construir una economía de mercado, en 1992, el legislador chino estableció varias leyes civiles y comerciales especiales en vez de darse la tarea de redactar un Código Civil. Las leyes civiles y comerciales especiales más importantes promulgadas y/o modificadas desde 1986 hasta ahora son: la Ley de Quiebra de Empresas, de 1986 (modificada el 2006) ${ }^{8}$; la Ley de Propiedad Intelectual, de 1990 (modificada el 2001)9 ; la Ley de Adopciones, de

\footnotetext{
${ }^{6}$ Principios Generales de Derecho Civil (promulgados por el Congreso Popular Nacional, 12 abril 1986, vigente 1 enero 1987), LAWINFOCHINA (última visita el 30 de enero de 2009). Los PGDC resuelven el conflicto entre el Derecho Civil y el Derecho Económico aceptando el antes mencionado planteamiento de los profesores de Derecho Civil chino sobre la jurisdicción del Derecho Civil; y contienen, además, muchas ideas de raigambre china y socialista. Por ejemplo, el artículo 7 dice que "[l]as actividades civiles deben tener respeto por la ética social y no deben dañar el interés público, socavar los planes económicos estatales o quebrantar el orden económico-social'. El artículo 6 cualifica las políticas estatales como una fuente del Derecho Civil. El artículo 134 incluye la eliminación de efectos nocivos, la rehabilitación de la reputación y el ofrecimiento de disculpas como medios que modulan la responsabilidad civil.

7 En el Derecho chino, el término "norma fundamental" se refiere a la ley, salvo el Derecho Constitucional, adoptada por la reunión plenaria del Congreso Popular Nacional, cuya modificación también está sujeta a la aprobación de tal reunión plenaria.

${ }^{8}$ Ley de Quiebra de Empresas (promulgada por el Comité Permanente del Congreso Popular Nacional, 27 agosto 2006, vigente 1 junio 2007), LAWINFOCHINA (última visita el 30 de enero de 2009).

${ }^{9}$ Ley de Propiedad Intelectual (promulgada como modificación por el Comité Permanente del Congreso Popular Nacional, 27 octubre 2001, vigente 1 junio 1991), LAWINFOCHINA (última visita el 30 de enero de 2009).
} 
199110; la Ley de Sociedades, de 1993 (modificada en 1999, 2004 y 2005) ${ }^{11}$; la Ley sobre Instrumentos Negociables (modificada el 2004)12; la Ley sobre Garantías, de 199513; la Ley de Seguros, de 1995 (modificada el 2009)14; la Ley de Compra de Acciones, de 1996 (modificada el 2004)15; Ley de Sociedades Comerciales, de 1997 (modificada el 2006) ${ }^{16}$; la Ley de Valores, de 1998 (modificada el 2005) ${ }^{17}$; la Ley de Contratación, de 1999 ${ }^{18}$; la Ley de Empresas de Propiedad Individual, de 199919; la Ley sobre Trust, de 200120; la Ley de Matrimonio, de 1980 (modificada el 2001)21; la Ley sobre Contrato de Trabajo, de 200722; y la Ley sobre Derechos Reales, de $2007^{23}$.

${ }^{10}$ Ley de Adopciones (promulgada por el Comité Permanente del Congreso Popular Nacional, 29 diciembre 1991, vigente 1 abril 1992, revisada 4 noviembre 1998), LAWINFOCHINA (última visita el 30 de enero de 2009).

${ }^{11}$ Ley de Sociedades (promulgada como modificación por el Comité Permanente del Congreso Popular Nacional, 27 octubre 2005, vigente 1 enero 2006), LAWINFOCHINA (última visita el 30 de enero de 2009).

${ }^{12}$ Ley sobre Instrumentos Negociables (promulgada como modificación por el Comité Permanente del Congreso Popular Nacional, revisada 28 agosto 2004, vigente 1 enero 1996), LAWINFOCHINA (última visita el 30 de enero de 2009).

${ }^{13}$ Ley sobre Garantías (promulgada por el Comité Permanente del Congreso Popular Nacional, 30 junio 1995, vigente 1 octubre 1995), LAWINFOCHINA (última visita el 30 de enero de 2009).

${ }^{14}$ Ley de Seguros (promulgada como modificación por el Comité Permanente del Congreso Popular Nacional, 28 febrero 2009, vigente 1 octubre 1995), LAWINFOCHINA (última visita el 30 de marzo de 2009).

${ }^{15}$ Ley de Compra de Acciones (promulgada como modificación por el Comité Permanente del Congreso Popular Nacional, 28 agosto 2004, vigente 1 enero 1997, revisada 28 agosto 2004), LAWINFOCHINA (última visita el 30 de enero de 2009).

${ }^{16}$ Ley de Sociedades Comerciales (promulgada como modificación por el Comité Permanente del Congreso Popular Nacional, 27 agosto 2006, vigente 1 junio 2007), LAWINFOCHINA (última visita el 30 de enero de 2009).

${ }^{17}$ Ley de Valores (promulgada como modificación por el Comité Permanente del Congreso Popular Nacional, 27 octubre 2005, vigente 1 julio 1999), LAWINFOCHINA (última visita el 30 de enero de 2009).

${ }^{18}$ Ley de Contratación (promulgada por el Congreso Popular Nacional, 15 marzo 1999, vigente 1 octubre 1999), LAWINFOCHINA (última visita el 30 de enero de 2009). La promulgación de esta ley unificada de contratación puso fin a la preexistente separación entre la Ley Económica de Contratación, la Ley Económica de Contratación relativa a Intereses Extranjeros y la Ley de Contratos sobre Tecnología (promulgada por el Comité Permanente del Congreso Popular Nacional, 23 junio 1987, vigente 1 noviembre 1987), LAWINFOCHINA (última visita el 30 de enero de 2009).

${ }^{19}$ Ley de Empresas de Propiedad Individual (promulgada por el Comité Permanente del Congreso Popular Nacional, 30 agosto 1999, vigente 1 enero 2000), LAWINFOCHINA (última visita el 30 de enero de 2009).

${ }^{20}$ Ley sobre Trust (promulgada por el Comité Permanente del Congreso Popular Nacional, 28 abril 2001, vigente 1 octubre 2001), LAWINFOCHINA (última visita el 30 de enero de 2009).

${ }^{21}$ Ley de Matrimonio (promulgada como modificación por el Comité Permanente del Congreso Popular Nacional, 28 abril 2001, vigente 1 enero 1981), LAWINFOCHINA (última visita el 30 de enero de 2009).

${ }^{22}$ Ley sobre Contrato de Trabajo (promulgada por el Comité Permanente del Congreso Popular Nacional, 29 junio 2007, vigente 1 enero 2008), LAWINFOCHINA (última visita el 30 de enero de 2009).

${ }^{23}$ Ley sobre Derechos Reales (promulgada por el Congreso Popular Nacional, 16 marzo 2007, vigente 1 octubre 2007), LAWINFOCHINA (última visita el 30 de enero de 2009). Aunque la Ley sobre Derechos Reales de 2007 regula en detalle los Derechos de Garantía para las obligaciones (en los artículos 170-240), su promulgación no abrogó la Ley de Garantías del año 1995. De acuerdo con el artículo 178 de la Ley sobre Derechos Reales de 2007, todas las disposiciones de la Ley de Garantías de 1995, excepto aquellas que pugnen con ella, todavía están en vigor. Sin embargo, por otro lado, la legislatura no ha clarificado en términos concretos qué partes de la Ley de Garantías de 1995 están en pugna con la Ley sobre Derechos Reales de 2007 y son, en consecuencia, inválidas. Para asegurar la correcta aplicación de estas dos leyes, los jueces todavía requieren las interpretaciones judiciales pertinentes dictadas por la Corte Suprema. 
Además de las leyes civiles y comerciales especiales, el Derecho Público de China -en particular, las leyes administrativas y las reglamentaciones de gobierno-, también disciplinan las relaciones civiles y comerciales. Por ejemplo, excepto para la Ley de Garantías, de $1995^{24}$, y la Ley sobre Derechos Reales, de $2007^{25}$, muchas leyes o reglamentos administrativos rigen también sobre las relaciones de propiedad; como la Ley de Administración de la Tierra, de 1986 (modificada el 1988, 1998 y 2004) ${ }^{26}$, la Ley sobre Administración de Inmuebles Urbanos, de 1994 (modificada el 2007) 27, la Ley de Contratación sobre Inmuebles Rurales, del $2003^{28}$, y las Medidas para el Registro de Hipotecas Mobiliarias ${ }^{29}$ promulgadas por la Administración del Estado para la Industria y el Comercio.

\section{LAS INTERPRETACIONES JUDICIALES}

Existen dos tipos de interpretaciones realizadas por los cuerpos judiciales de China. El primer tipo consiste en las respuestas de la Corte Suprema a una Corte inferior en relación a un caso concreto, o las opiniones directivas (o anuncios) sobre un problema concreto cuya solución no es clara o no está regulada en la ley ${ }^{30}$. Por ejemplo, aunque el

${ }^{24}$ Ley de Garantías (promulgada por el Comité Permanente del Congreso Popular Nacional, 30 junio 1995, vigente 1 octubre 1995), LAWINFOCHINA (última visita el 30 de enero de 2009).

25 Ley sobre Derechos Reales (promulgada por el Congreso Popular Nacional, 16 marzo 2007, vigente 1 octubre 2007), LAWINFOCHINA (última visita el 30 de enero de 2009).

${ }^{26}$ Ley sobre Administración de la Tierra (promulgada por el Comité Permanente del Congreso Popular Nacional, 20 agosto 1998, vigente 1 enero 1999, modificada 28 agosto 2004), LAWINFOCHINA (última visita el 30 de enero de 2009).

${ }^{27}$ Ley sobre Administración de Inmuebles Urbanos (promulgada por el Comité Permanente del Congreso Popular Nacional, 30 agosto 2007, vigente 1 enero 1995), LAWINFOCHINA (última visita el 1 de enero de 2009).

28 Ley de Contratación sobre Inmuebles Rurales (promulgada por el Comité Permanente del Congreso Popular Nacional, 29 agosto 2002, vigente 1 marzo 2003), LAWINFOCHINA (última visita el 30 de enero de 2009).

${ }^{29}$ Medidas para el Registro de Hipotecas Mobiliarias (promulgadas por la Administración Estatal para la Industria y el Comercio, 17 octubre 2007, vigentes 17 octubre 2007), LAWINFOCHINA (última visita el 30 de enero de 2009).

${ }^{30}$ V. g., "Respuesta Oficial de la Corte Popular Suprema Sobre Si Debe Surgir Responsabilidad Civil por la Infracción en el Derecho Básico del Ciudadano de Recibir Educación, el cual está Bajo la Protección de la Constitución, por Medio de la Vulneración de su Derecho al Nombre (24 de julio de 2001)", LAWINFOCHINA (última visita el 30 de enero de 2009). Esta fue la primera vez que la Corte Suprema citó la Constitución de la RPC para fundamentar la infracción de derechos civiles. El caso se refiere a la pérdida de la oportunidad de recibir educación en la Escuela de Negocios de Jining, en la Provincia de Shandong, por la Srta. Qi Yuling, la hija de un campesino. Después de recibir la notificación de la admisión de la Srta. Qi Yuling para estudiar en la mencionada escuela de negocios, el Sr. Cheng Kezheng, el jefe del pueblo de la Srta. Qi Yuling, no le entregó a esta dicha notificación, sino que, en cambio, envió a su propia hija a estudiar a la escuela de negocios utilizando el nombre de la hija del campesino. En esta causa, por requerimiento de la Alta Corte de la Provincia de Shandong, la Corte Suprema expidió una respuesta en la que sostuvo que las conductas del jefe del pueblo, de su hija, de la escuela secundaria y de la escuela de negocios habían violado el derecho cívico a recibir educación, el cual es un derecho fundamental protegido por la Constitución de la RPC. Sin embargo, la Corte Suprema inesperadamente revocó su respuesta, el 18 de diciembre de 2008, sin fundamentación alguna. Tal decisión de la Corte Suprema provocó muchos debates entre los especialistas del Derecho. Algunos académicos sostuvieron que la revocación de esta 
Proyecto de Ley sobre Derecho de Daños chino todavía se encuentre en proceso de elaboración, en los años recientes la Corte Suprema ha dictado importantes interpretaciones judiciales sobre cómo tratar los casos relativos a dicha responsabilidad; tal como se puede ver en la "Interpretación de la Corte Popular Suprema en Varios Dictámenes sobre el Juzgamiento de Casos Relativos al Derecho a la Reputación"; la "Interpretación de la Corte Popular Suprema sobre Problemas Relativos a la Determinación de la Indemnización en la Responsabilidad por Daños Emocionales"; y la "Interpretación de la Corte Popular Suprema sobre algunas Resoluciones Relativas a la Aplicación de la Ley para el Juzgamiento de Casos sobre Indemnización de Injurias Personales" 31.

El segundo tipo de interpretación judicial busca establecer regulaciones para la implementación de una ley existente con el objeto de hacerla aplicable a los casos concretos, dado que muchas disposiciones de las leyes chinas son abstractas y producen diferentes interpretaciones en la práctica. Estas interpretaciones judiciales proporcionan comentarios sistemáticos a la ley, a veces casi artículo por artículo. Por ejemplo, los PGDC tienen solo 156 artículos, pero la interpretación que de ellos hizo la Corte Suprema, el 26 de enero de 1988, contiene más de 200 comentarios $^{32}$.

En cierto sentido, los comentarios sistemáticos a la ley de la Corte Suprema y sus opiniones directivas relativas a soluciones legales generales constituyen un ejercicio deformado de la potestad legislativa - un poder no concedido como tal al Poder Judicial bajo el Derecho Constitucional de China-. Hoy, incluso ante las críticas del Poder

respuesta fue correcta, ya que la Constitución de la RPC no permite a la Corte citar directamente sus artículos para tomar una decisión. Por el contrario, otros creyeron que esta decisión servía para conformar un índice de errores a tener en cuenta en la reforma judicial china que se encuentra en marcha. Para detalles sobre esta discusión, Han DaYUAn, Yi Xian Fa Di Yao Er Liu Tiao Wei Ji Chu Xun Qiu Xian Fa Shi Yong De Gong Shi [Convergencia en la Condición de Aplicación del Derecho Constitucional sobre la Base del Artículo 126 de la Constitución de la RPC], 2009 FA XUE YUE KAN [Boletín Mensual de Jurisprudencia] número 3, en 4; Dong Maoyun, Cong Fei Zhi Qi An "Pi Fu" Kan Si Fa Gai Ge De Fang Xiang [La orientación de la Reforma Judicial Vista a partir de la Revocación de la Respuesta en el Caso "Qi Yuling”], 2009 FA XUE YUE KAN [Boletín Mensual de Jurisprudencia] número 3, en 36.

31 "Interpretación de la Corte Popular Suprema sobre Varias Resoluciones sobre el Juzgamiento de Casos Relativos al Derecho a la Reputación” (14 julio 1998), LAWINFOCHINA (última visita el 1 de enero de 2009); "Interpretación de la Corte Popular Suprema sobre Problemas Relativos a la Determinación de la Compensación en la Responsabilidad por Daños Emocionales en los Delitos Civiles" (8 marzo 2001), LAWINFOCHINA (última visita el 30 de enero de 2009); "Interpretación de la Corte Popular Suprema sobre Algunas Resoluciones Relativas a la Aplicación de la Ley para el Juzgamiento de Casos sobre Compensación de Injurias Personales" (26 diciembre 2003), LAWINFOCHINA (última visita el 30 de enero de 2009).

32 Este tipo de interpretación judicial no solo concierne a los PGDC, sino también a la mayoría de algunas importantes leyes civiles especiales, como la Ley de Garantías, de 1995, la Ley de Matrimonio, de 2001, y la Ley de Contratación, de 1999. Vid. "Interpretación de la Corte Popular Suprema en la Aplicación de la Ley de Garantías" (29 septiembre 2000), discutida en http://english.peopledaily.com.cn/english/200012/14/ eng20001214_57828.html (última visita el 30 de enero de 2009); "Interpretación de la Corte Popular Suprema en Varias Resoluciones Concernientes a la Aplicación de la Interpretación de la Ley de Contración de la RPC (1)" (29 diciembre 1999), disponible en http://www.chinalawandpractice.com/Article/1694665/ Channel/9929/Supreme-Peoples-Court-Several-Issues-Concerning-Application-of-the-PRC-Contract-LawInterpretation-1.html (última visita el 30 de enero de 2009); "Interpretación $N^{o}$ I de la Corte Popular Suprema sobre Varias Resoluciones en la Aplicación de la Ley de Matrimonio" (25 diciembre 2001), LAWINFOCHINA (última visita el 30 de enero de 2009). 
Legislativo y de los académicos, la Corte Suprema continúa expidiendo muchas interpretaciones judiciales. Por otro lado, China no tiene un poder independiente, como un Tribunal Constitucional, para asegurar la legitimidad constitucional de las leyes y de las interpretaciones judiciales. Por consiguiente, son de común ocurrencia los conflictos e incluso contradicciones entre las leyes chinas y sus respectivos reglamentos o interpretaciones judiciales. Y, por tanto, tales conflictos constituyen un serio obstáculo a la realización del imperio del Derecho en China.

Dejando a un lado su constitucionalidad, estas interpretaciones judiciales, con el propósito de resolver problemas jurídicos concretos, clarifican el significado de las disposiciones establecidas por la ley y guían a los jueces y otros operadores legales en la implementación eficiente del Derecho Civil. Cualquier abogado que deba hacerse cargo de una causa civil concreta en China, debe consultar esas interpretaciones de la Corte Suprema, las cuales se basan tanto en la experiencia práctica como en los informes consultivos entregados por profesores de Derecho. Es más, estas interpretaciones se transforman en reglas jurisprudenciales (stare decisis), y, en este sentido, el Derecho Civil chino es similar al derecho de precedentes (case law).

\section{LOS ÚLTIMOS AVANCES EN LA CODIFICACIÓN DEL DERECHO CIVIL $\mathrm{CHINO}$}

Actualmente, China está elaborando un Código Civil cuyo proyecto comenzó en 1998. Con el propósito de armonizar las leyes civiles existentes y sus interpretaciones judiciales, así como con el de garantizar su correcta y eficiente aplicación, el Comité Permanente del Congreso Popular Nacional decidió, en 1998, adoptar tres etapas para lograr la codificación del Derecho Civil chino el año 2010.

Primero, promulgó y modificó las leyes civiles más importantes en orden a la creación de normas unificadas sobre el comercio de mercado y la protección de los derechos reales y personales. El Poder Legislativo programó la siguiente agenda relativa a la codificación del Derecho Civil: la unificación de las leyes de contratación (llamadas: Ley Económica de Contratación, de 198133; Ley Económica de Contratación relativa a Intereses Extranjeros, de 198534; y Ley de Contratos sobre Tecnología, de 198735); la modificación de la Ley de Matrimonio, de 198036; y la preparación y promulgación de una Ley sobre Derechos Reales, una sobre Derecho de Daños (si es necesario), una Ley de Derechos de la Personalidad y, por último, una Ley unificada de Propiedad Intelec-

\footnotetext{
${ }^{33}$ Ley Económica de Contratación (promulgada por el Comité Permanente del Congreso Popular Nacional, 13 diciembre 1981, vigente 1 julio 1982), LAWINFOCHINA (última visita el 30 de enero de 2009).

${ }^{34}$ Ley Económica de Contratación relativa a Intereses Extranjeros (promulgada por el Comité Permanente del Congreso Popular Nacional, 21 marzo 1985, vigente 1 julio 1985), LAWINFOCHINA (última visita el 30 de enero de 2009).

${ }^{35}$ Ley de Contratos sobre Tecnología (promulgada por el Comité Permanente del Congreso Popular Nacional, 23 junio 1987, vigente 1 noviembre 1987), LAWINFOCHINA (última visita el 30 de enero de 2009).

36 Ley de Matrimonio (promulgada como modificación por el Comité Permanente del Congreso Popular Nacional, 28 abril 2001, vigente 1 enero 1981), LAWINFOCHINA (última visita el 30 de enero de 2009).
} 
tual. Segundo, el Congreso decidió elaborar la Parte General del Código Civil chino sobre la base de los PGDC. Finalmente, optó por completar el Proyecto de Código Civil chino combinando sistemáticamente todas las leyes civiles especiales con la Parte General del Código Civil.

Aunque parezca imposible realizar esta codificación en el tiempo programado, faltando solo un año para el final de 2010, la codificación en marcha del Derecho Civil chino ya ha alcanzado algunos resultados significativos: la Ley unificada de Contratación ${ }^{37}$, que fue promulgada en 1999; la Ley de Matrimonio, de $1980^{38}$, que fue modificada en el 2001; un texto del Proyecto de Código Civil, que fue terminado y presentado al Congreso Popular Nacional el año 2002; y la Ley sobre Derechos Reales, que fue promulgada el 2007. Por último, actualmente China está preparando su Ley de Daños, y planea promulgarla el 2010. En consecuencia, los últimos avances en la codificación del Derecho Civil chino consisten en la Ley sobre Derechos Reales, del 2007, y la actual preparación de una Ley de Daños.

Pero, sin perjuicio de lo anterior, antes de discutir aquellos hitos legislativos -la Ley sobre Derechos Reales, de 2007, y la actual situación respecto de la preparación de la Ley de Daños-, debo describir brevemente el Proyecto de Código Civil de 2002 y los debates correspondientes, pues constituyen el texto de trabajo fundamental para toda la subsiguiente codificación en China después de dicho año.

\section{A. Debates sobre la estructura de un futuro Código Civil de CHINA}

A comienzos del siglo veintiuno, el desarrollo socioeconómico de China, la profundización de la reforma y la apertura del país han sentado una sólida base social para el Código Civil, a partir de la cual el legislador chino planeó completar su Proyecto. Desde el 2000, los debates sobre la estructura del Código Civil chino han constituido un tema central de investigación para los académicos del Derecho Civil.

El profesor Jiang Ping, uno de los más famosos profesores de Derecho en China, afirma que el modelo tradicional de Código Civil continental es muy rígido para satisfacer las necesidades del desarrollo de una sociedad moderna; y, en consecuencia, que el futuro Código Civil chino debe ser más elástico en orden a comprender las ventajas del common law ${ }^{39}$. Debido a la complejidad de las relaciones jurídicas que el Derecho Civil

37 Ley de Contratación (promulgada por el Congreso Popular Nacional, 15 marzo 1999, vigente 1 octubre 1999), LAWINFOCHINA (última visita el 30 de enero de 2009).

38 Ley de Matrimonio (promulgada como modificación por el Comité Permanente del Congreso Popular Nacional, 28 abril 2001, vigente 1 enero 1981), LAWINFOCHINA (última visita el 30 de enero de 2009).

39 Jiang Ping, Zhong Guo Min Fa Dian Zhi Ding De Hong Guan Si Kao [Reflexiones Generales sobre el Avance del Proyecto de Código Civil Chino], 2002 FA XUE YUE KAN [BOLETÍN MENSUAL DE JURISPRUDENCIA] número 2, en 41. Luego del Proyecto de Código Civil de 2002, el profesor Jiang Ping continuó defendiendo esta posición. Ver Jiang Ping, Min Fa De Hui Gu He Zhan Wang [Derecho Civil, Retrospectiva y Perspectiva], 2006 BI JIAO FA YAN JIU [Revista de Derecho Comparado] número 2. 1, en 1 [En lo sucesivo, Jiang Ping, Retrospectiva y Prospectiva]; Jiang Ping, Zhi Ding Yi Bu Kai Fang Xing De Min Fa Dian [Proyección de un Código Civil de Estilo Abierto, 2003 ZHENG FA LUN TAN 
actual regula -continúa-, sería imposible disciplinar todas ellas en este Código Civil. Por lo tanto, este debiere ser un pequeño Código que regule los más importantes principios e instituciones civiles de una manera abstracta. De modo que bajo este Código Civil, dotado de disposiciones generales, habrán de armonizarse muchas leyes civiles especiales e interpretaciones judiciales. Esta estructura se considera como una vía pragmática para la codificación ${ }^{40}$.

Sin embargo, dicha idea es radicalmente cuestionada por otro prominente profesor de Derecho Civil, el profesor Liang Huixing. En opinión de Liang, el futuro Código Civil debe adoptar la sistematización del BGB y, en consecuencia, disponer muchas disposiciones detalladas para la regulación de las relaciones jurídicas civiles. Esta visión se sustenta en el hecho de que la legislación china, la investigación y la enseñanza del Derecho Civil están basadas en los conceptos jurídicos y los principios del Derecho alemán, y en que el BGB es el fruto de más alto nivel en la investigación del Derecho Civil moderno. Además, China necesitaría un Código con muchos artículos detallados considerando el bajo nivel de instrucción jurídica que los jueces chinos han recibido ${ }^{41}$. Por esta razón, el profesor Liang propone la siguiente estructura para el futuro Código Civil chino: I. Parte General; II. Derechos reales; III. Obligaciones parte general; IV. Contratos; V. Daños; VI. Derecho de Familia; y VII. Sucesiones ${ }^{42}$. Inspirado por la experiencia codificadora del Código Civil holandés de 1992 y el Código Civil ruso de 2001, él sugiere dividir la parte tradicional sobre obligaciones en tres partes: Parte General de las Obligaciones, Contratos y Daños ${ }^{43}$.

De la misma forma, otro prominente académico de Derecho Civil, el profesor Wang Liming, argumenta que el Código Civil chino debe estructurarse principalmente en base a la experiencia codificadora alemana y al resultado de la investigación en el pandectenrecht [Derecho de Pandectas]. Al mismo tiempo, el profesor Wang sostiene que el Código Civil chino debiera reforzar la protección de los derechos de la personalidad, cuya carencia es un defecto del BGB, mediante la inclusión de una parte separada llamada Derechos de la Personalidad; incorporando esta parte antes de las disposiciones sobre el derecho de propiedad. Así, el profesor Wang daría la siguiente estructura siste-

[TRIBUNA DE CIENCIA POLÍTICA Y DERECHO] número 1, en 1 [En lo sucesivo, Jiang Ping, Código de Estilo Abierto]; Jiang Ping, Zai Tan Zhi Ding Yi Bu Kai Fang Xing De Min Fa Dian [Más sobre Proyectar un Código Civil de Estilo Abierto], 2003 FA XUE JIA [REVISTA DE JURISTAS] número 4, en 1 [En lo sucesivo, Jiang Ping, Más sobre un Código de Estilo Abierto].

40 Jiang Ping, Más sobre un Código de Estilo Abierto, supra nota 39, en 1; Liang Huixing, Dang Qian Guan Yu Min Fa Dian Bian Zuan De San Tiao Si Lu [Las Tres Ideas Principales sobre la Codificación del Derecho Civil Chino], 2003 LÜ SHI SHI JIE [MUNDO DEL ABOGADO] número 2, en 4.

41 Ver Liang Huixing, supra nota 40, en 1; Liang Huixing, Zhi Ding Min Fa Dian De She Xiang [Observaciones sobre la Creación de un Código Civil para China], 2001 XIAN DAI FA XUE [CIENCIA JURÍDICA MODERNA] número 2, en 5. Estas ideas ya habían sido expresadas algunos años antes. Ver Liang Huixing, Guan Yu Zhi Ding Zhong Guo Min Fa Dian De Si Kao [Reflexiones Acerca de la Evolución del Proyecto de Código Civil Chino], REN MIN FA YUAN BAO [BOLETÍN DE LA CORTE POPULAR], febrero 12, 2000, disponible en http://law.thinker.com/news.php?id=2274.

42 Liang Huixing, supra nota 40, en 3.

${ }^{43}$ Liang Huixing, en 5. 
mática al futuro Código Civil chino: I. Parte General; II. Derechos de la personalidad; III. Matrimonio y familia; IV. Sucesiones; V. Derechos reales; VI. Obligaciones parte general; VII. Contratos; y VIII. Daños ${ }^{44}$.

Otros profesores de Derecho Civil se oponen a la idea de seguir el modelo alemán de codificación y, en cambio, están a favor de la adopción del Code Napoléon; ello en consideración de que dicho Código preserva la tradicional división del ius civile en "persona-res-actio" de las Gai Institutiones y, al hilo de lo anterior, da un mayor énfasis a la importancia del valor de la persona en el Derecho Civil ${ }^{45}$.

De acuerdo con esta opinión, el futuro Código Civil chino debiere constar de cuatro partes: I. Disposiciones Generales; II. Relaciones personales (con cuatro capítulos: Individuo, Relaciones domésticas, Personas jurídicas y Sucesiones); III. Relaciones de propiedad (con cuatro capítulos: Derechos reales, Derechos del acreedor, Contratos y Propiedad intelectual); y IV. Disposiciones suplementarias (incluyendo la aplicación de la ley en las relaciones civiles con extranjeros $)^{46}$. Asimismo, algunos otros profesores chinos de Derechos Civil también están de acuerdo en que el futuro Código debiera constar de cuatro partes, pero con distintos encabezados: I. Prefacio; II. Derecho de personas (con cuatro capítulos: Disposiciones generales, Individuo, Personas jurídicas y otros Sujetos de Derecho); III. Derechos [Subjetivos] (con seis capítulos: Derechos de la Personalidad, Derechos relativos a las Relaciones Domésticas, Derecho de Sucesión, Propiedad Intelectual, Derecho de Obligaciones y Derechos Reales); y IV. Derecho de Daños ${ }^{47}$.

\section{B. Proyecto de Código Civil de 2002}

El Comité Permanente del Congreso Popular Nacional, luego de una intensa discusión con los académicos del Derecho, aceptó la visión pragmática de la codificación del profesor Jiang Ping; y, bajo esa inspiración, el 23 de diciembre de 2002 estableció el Primer Proyecto de Código Civil. ${ }^{48}$ De acuerdo a la estructura sistemática de este Pro-

44 WANG LIMING, ZHONG GUO MIN FA DIAN CAO AN JIAN YI GAO JI SHUO MING [Proyecto Consultivo de Código Civil de la RPC y sus Anotaciones] 274 (2004); Wang Liming, Shi Lun Wo Guo Ming Fa Dian Ti Xi [Sobre la Estructura del Código Civil Chino, 2003 ZHENG FA LUN TAN [TRIBUNA DE CIENCIA POLÍTICA Y DERECHO] núnero 1, en 23.

45 THE CODE NAPOLEON (Bryant Barrett trans., Gray's Inn 1811) (1804).

${ }^{46}$ Xu Guodong, Min Fa Dian Cao An De Ji Ben Jie Gou [La Estructura Básica del Futuro Código Civil Chino], 2000 FA XUE YAN JIU [REVISTA CHINA DE DERECHO] número 2, en 45.

${ }_{77} \mathrm{Ma}$ Changhua \& Qin Youtu, Lun Wo Guo Min Fa Dian De Ti Xi Jie Gou [Sobre la Estructura del Código Civil Chino], 2004 FA XUE YUE KAN [BOLETÍN MENSUAL DE JURISPRUDENCIA] número 2 , en 54 .

${ }^{48}$ Véase Liang Huixing, Zhong Guo Min Fa Dian Bian Zuan Yu Zheng Lun Dian [Sobre el Proceso de Codificación del Derecho Civil Chino y las Divergencias Relacionadas], enero. 5, 2003, http:// www.ccelaws.com/minshifaxue/2009-01-01/2601.html (con discusión sobre la preparación del Proyecto de Código Civil de 2002); Wang Shengming, Fa Zhi Guo Jia De Bi You Zhi Lu- Bian Zhuang Zhong Hua Ren Ming Gong He Guo Min Fa (Cao An) De Ji Ge Wen Ti [El Camino que un País Respetuoso del Derecho ("con Imperio del Derecho") Debe Seguir: Algunos Problemas sobre la Preparación del Proyecto de Código Civil de la RPC], 2003 ZHENG FA LUN TAN [TRIBUNA DE CIENCIA POLÍtiCA Y DERECHO] número 2, en 26, 27 (con discusión sobre la intruducción general del Proyecto de Código Civil de 2002). 
yecto, que consta de 1.209 artículos, el Código Civil chino se dividirá en nueve partes: I. Parte General (117 arts.); II. Derechos Reales (330 arts.); III. Contratos (428 arts.); IV. Derechos de la Personalidad (29 arts.); V. Matrimonio (51 arts.); VI. Adopción (34 arts.); VII. Sucesiones (37 arts.); VIII. Daños; y IX. Aplicación de normas civiles que conciernen al interés extranjero (95 arts.). El legislador y la mayoría de los académicos creen que este Proyecto será sustancial y efectivamente el nuevo Código, el cual tendrá carácter unificador, pues versará no solo sobre el Derecho Civil, sino también sobre el Derecho Comercial. El Proyecto de Código Civil de 2002 constituye, por tanto, el documento de trabajo básico para la futura codificación del Derecho Civil en China; incluso siendo solo un documento de trabajo provisional y preliminar. Su estructura y contenido demuestran la fuerte influencia del common law en el Derecho Civil chino, de la forma que se trata a continuación.

Primero, no es un Código Civil continental tradicional, pues contiene una estructura amplia y de menor rigidez sistemática; a pesar de que en su base se adoptaron principalmente los conceptos e instituciones jurídicas del Derecho continental. Sus nueve partes han sido preparadas separadamente, y ninguna de ellas hace referencia a las otras. La Parte General proviene directamente del los PGDC, solo con algunas ligeras enmiendas: la Ley de Contratos de 1999 constituye la tercera parte del Proyecto, "Contratos"; La ley Matrimonial de 1980, modificada el 2001, es incorporada sin modificación alguna al Proyecto bajo el título "Matrimonio"; y lo mismo sucedió con la Ley de Adopción de 1991 y la Ley de Sucesiones de 1985. Así, el proyecto puede ser considerado como un ensamble mecánico de sus nueve partes. Este pragmático método de codificación se justifica por el hecho de que China ha promulgado muchas leyes civiles especiales previas a su decisión de elaborar un Código Civil, y a que la función más importante de la codificación china es la armonización de las leyes existentes con sus interpretaciones judiciales.

Segundo, de manera similar al common law, el Proyecto de Código Civil de 2002 no tiene una sección sobre Obligaciones, sino más bien dos partes: Contratos y Daños, titulada en el Proyecto como "Responsabilidad por Daños". Importantes académicos chinos justifican la elección de solo dedicar una parte independiente a los contratos y otra a los daños por tres razones ${ }^{49}$. En primer lugar, las obligaciones surgen frecuente y principalmente de las relaciones contractuales o de la responsabilidad por daños, y ocasional y accidentalmente de una negotiorum gestio y del enriquecimiento sin causa. Las dos primeras especies de relaciones son bastante más complicadas que las segundas, justificando la dedicación de una parte especial para cada una de ellas en el Código. En segundo lugar, las obligaciones contractuales son bastante diferentes a las de los daños porque: (1) la existencia de responsabilidad contractual requiere el incumplimiento de deberes contractuales. Generalmente, esos deberes son respecto a un sujeto jurídico determinable, más que respecto de toda persona, y el contenido de esos deberes es fijado por las partes mediante la expresión de su consentimiento; (2) por otra parte, no existe

49 WANG LIMING, supra nota 44, en 275; Liang Huixing, supra nota 40, en 8. 
responsabilidad por daños sin una previa infracción de un derecho absoluto cuyo contenido no es definido por las partes sino por la ley; (3) en general, la responsabilidad contractual es una responsabilidad estricta, en el sentido de que la parte incumplidora es responsable por el quebrantamiento del contrato incluso no siendo culpable, a menos que exista una causal de exoneración de responsabilidad. Sin embargo, en el campo del Derecho de Daños, la culpa es un factor fundamental para la determinación de la responsabilidad, y la responsabilidad estricta o la inversión de la carga probatoria son excepcionales; y (4) debido a la libertad contractual, las partes contratantes pueden consensualmente liberarse de la responsabilidad contractual antes del cumplimiento de las obligaciones. Sin embargo, esto es imposible en el caso de las obligaciones provenientes de los daños. Varios académicos chinos argumentan que el hecho de que la responsabilidad por daños sea una parte independiente en el Proyecto prueba la fuerte influencia del common law ${ }^{50}$. En tercer lugar, la ausencia de una Parte General sobre las Obligaciones en el Proyecto de Código Civil de 2002 también está justificada, ya que las disposiciones de esta parte se superpondrían con las disposiciones relativas a los contratos y esto [la integración a la materia contractual de derechos legales - no pactados- establecidos en una Parte General de las Obligaciones, que en cuanto tales se miran como indisponibles desde esta perspectiva] haría difícil distinguir los "derechos del acreedor" [de carácter convencional] de los "derechos reales" [de carácter legal] ${ }^{51}$. Sin embargo, algunos académicos agudamente criticaron la ausencia de una Parte General sobre las Obligaciones en el Proyecto de Código Civil de 2002, argumentando que el concepto de "obligación" es fundamental en el Derecho Civil. Ellos sostienen que la Parte General sobre Obligaciones es necesaria para que el Código Civil tenga una estructura lógica y sistemática adecuada, porque es una parte imprescindible para regular las relaciones prestacionales de propiedad, siendo aplicable no solo a los contratos y daños sino también al enriquecimiento sin causa y a la negotiorum gestio ${ }^{52}$.

En tercer lugar, el Proyecto incluye varios conceptos e instituciones importantes del common law. Por ejemplo, el Proyecto adopta el concepto de "quebrantamiento del contrato" (breach of contract) más que el de "incumplimiento de la obligación"

\footnotetext{
${ }^{50}$ Jiang Ping, Código de Estilo Abierto, supra nota 39, en 2; Jiang Ping, Más sobre un Código de Estilo Abierto, supra nota 39, en 2.

${ }^{51}$ Qin Youtu \& Ma Chang Hua, Wo Guo Min Fa Dian Zhong Zhai Fa Zong Ze De Cun Fei [Las Ventajas y Desventajas de Disponer una Parte General de las Obligaciones en el Código Civil Chino], 2003 FA XUE YUE KAN [BOLETÍN MENSUAL DE JURISPRUDENCIA] número 5, en 101, 104. El profesor Jiang Ping también sostuvo esa posición, de acuerdo al reporte de Shi Ji Jing Ji Bao Dao [Heraldo del Siglo Veintiuno]. Fa Xue Quan Wei Cun Zai Zheng Yi, Min Fa Dian Chu Tai Kun Nan Chong Chong [Divergencias entre los más Importantes Juristas, la Dificultad de la Promulgación del Código Civil], SHI JI JING JI BAO DAO [HERALDO DEL SIGLO VEINTIUNO], enero. 5, 2003, disponible en http:// www.shjubao.cn/epublish/gb/paper148/20030105/class014800018/hwz859638.htm; ver también Jiang Ping, Retrospectiva y Perspectiva, supra nota 39, en 20.

52 Liang Huixing, supra nota 40, en 8; Wang Liming, Shi Lun Wo Guo Min Fa Dian Ti Xi [ Sobre la Estructura del Código Civil Chino], 2003 ZHENG FA LUN TAN [TRIBUNA DE CIENCIA POLÍTICA Y DERECHO] número 1, en 24; véase Liu Jingwei, Min Fa Dian Zhai Fa Li Fa Ti Xi Yan Jiu [Estudios sobre el Sistema Legislativo de las Obligaciones en el Código Civil], http://www.civillaw.com.cn/article/ default.asp?id=42987 (última visita el 2 de febrero de 2009).
} 
(Leistungstörung) del Derecho Civil continental, e incluye algunas instituciones típicas del common law, como el quebrantamiento anticipado de contrato (anticipatory breach of contract) ${ }^{53}$, la agencia encubierta [mandato a nombre propio] ${ }^{54}$ (undisclosed agency), la prenda flotante (floating charge) ${ }^{55}$, y la protección de la privacidad ${ }^{56}$.

En cuarto lugar, este Proyecto también se caracteriza por su quinta parte, llamada "Derechos de la Personalidad", la cual constituye una invención china completamente original ${ }^{57}$. Actualmente, ningún Código Civil en el mundo regula los derechos de la

53 El artículo 108 de la tercera parte del Proyecto, "Contratos" - llamado el Derecho de Contratos de 1999-, dispone: "Cuando una parte contractual exprese explícitamente o a través de sus actos que no cumplirá el contrato, la otra parte podrá exigirle soportar la responsabilidad por el quebrantamiento del contrato antes del vencimiento del plazo para el cumplimiento." Proyecto de Código Civil de 2002, t. III, art. 108 (sometido al Congreso Popular Nacional, diciembre 23, 2002).

${ }^{54}$ El artículo 402 de la tercera parte del proyecto, "Contratos", llamado el Derecho de Contratos de 1999, dice: "Cuando el agente [mandatario], actuando dentro del alcance autorizado por el principal [mandante], celebra un contrato bajo su propio nombre con una tercera persona que conocía de la relación de agencia entre el principal [mandante] y el agente [mandatario], el contrato es vinculante para el principal [mandante] y para esa tercera persona, salvo cuando exista evidencia determinante que establezca que el contrato es solo vinculante para el agente [mandatario] y la tercera persona". El artículo 403 dice: "Cuando el agente [mandatario] celebra un contrato bajo su propio nombre con una tercera persona que no conocía de la relación de agencia entre el agente [mandatario] y el principal [mandante], si el agente [mandatario] no cumple su obligación respecto del principal debido a cualquier razón atribuible a tal tercera persona, el agente [mandatario] deberá revelar (disclose) esta tercera persona al principal [mandante], permitiéndole ejercitar el derecho del agente [mandatario] en contra de esa tercera persona, salvo si la tercera persona no hubiese celebrado el contrato con el agente [mandatario] si hubiese sabido la identidad del principal [mandante]. Cuando el agente [mandatario] incumple su obligación respecto de la tercera persona debido a una razón atribuible al principal [mandante], el agente [mandatario] debe revelar (disclose) el principal [mandante] a la tercera persona, permitiéndole a la tercera persona elegir alternativamente al principal [mandante] o al agente [mandatario] como la otra parte del contrato contra la cual ejercer su pretensión, con la condición de que la tercera persona no pueda posteriormente cambiar su selección de la parte del contrato. Cuando el principal [mandante] ejerce los derechos del agente [mandatario] en contra la tercera persona, la tercera persona puede servirse de cualquier defensa que tenga contra el agente [mandatario]. Cuando la tercera persona elige al principal [mandante] como la otra parte del contrato, el principal [mandante] puede servirse de cualquier defensa que tenga en contra del agente [mandatario] como también cualquier defensa que tenga en contra de la tercera persona".

55 El artículo 241 de la parte sobre "Derechos Reales" del Proyecto dispone que "Las siguientes propiedades pueden ser utilizadas para hipotecas:... (2) Máquinas, medios de transporte y otras cosas.". El artículo 249 de la misma parte dice: "En el caso de que las partes hipotequen las siguientes cosas, estas deberán inscribir en un registro ante las autoridades competentes... (5) En el caso las máquinas u otros bienes muebles pertenecientes a un empresa, las partes deberán inscribir ante el registro del departamento administrativo para la industria y el comercio del lugar en el que la cosa hipotecada se encuentre".

56 El artículo 1 de la parte sobre "Derechos de la Personalidad" del Proyecto califica el derecho a la privacidad, junto con el derecho a la vida, el derecho al nombre, el derecho a la imagen, el derecho a la reputación, el derecho al honor y el derecho a la credibilidad, como los Derechos de la Personalidad pertenecientes la persona natural. El Proyecto también dedica todo el capítulo 7, llamado "Derecho a la privacidad" (arts. 25-29), en la parte de "Derechos de la Personalidad", para asegurar su protección.

${ }^{57} \mathrm{La}$ opinión prevaleciente es que el término jurídico "Derechos de la personalidad" (Ren Ge Quan, en chino; Persönlichkeitsrechte, en alemán) se refiere a los derechos exclusivos sobre el interés personal, que un individuo o persona jurídica debe tener para salvaguardar su autonomía personal. Los derechos de la personalidad de un individuo consisten en el derecho a la vida, el derecho a la salud, el derecho al nombre, el derecho a la imagen, el derecho de petición, el derecho a la reputación, el derecho a la credibilidad, el derecho al honor, el derecho a la libertad de comportamiento, el derecho a la privacidad, el derecho a la libertad matrimonial y el derecho a la libertad sexual. Véase YANG LIXIN, REN GE QUAN FA [Ley sobre 
personalidad en una parte independiente. Según algunos académicos chinos, los códigos civiles de Europa, tales como el Code Napoléon y el BGB no protegen suficientemente los derechos de la personalidad. Así, el futuro Código Civil chino, corrigiendo este defecto, superará el modelo europeo mediante el establecimiento de la parte independiente dedicada a los derechos de la personalidad. En esta parte, siguiendo la experiencia del common law, el legislador chino claramente provee no solo el derecho a la privacidad, sino también el derecho a la credibilidad ${ }^{58}$.

los Derechos de la Personalidad] 19 (2006) [en lo sucesivo YANG LIXIN, Derechos de la Personalidad]; YANG LIXIN, ZHONG GUO REN GE QUAN FA LI FA BAO GAO [REPORTE LEGISLATIVO SOBRE DERECHOS DE LA PERSONALIDAD EN CHINA] 241 (2005) [en lo sucesivo YANG LIXIN, REPORTE LEGISLATIVO]. Los derechos de familia y de la personalidad de una persona natural (Shen Fen Quan, en Chino, Persönliche Familienrechte en alemán) conforman sus derechos personales (Ren Shen Quan, en Chino, Persönlicherechte en alemán). Ver YANG LIXIN, DERECHOS DE LA PERSONALIDAD, supra, en 19; YANG LIXIN, REPORTE LEGISLATIVO, supra, en 241. En el Proyecto de Código Civil de 2002, el legislador chino enfatizó la importancia de la protección de los derechos de la personalidad dedicándoles una parte independiente. Esta parte está dividida en siete capítulos: (1) Disposiciones Generales (siete artículos), (2) Derechos a la Vida y a la Salud (cinco artículos), (3) Derechos al Nombre y a la Denominación (cuatro artículos), (4) Derecho a la imagen (dos artículos), (5) Derecho al Honor y a la Reputación (cuatro artículos), (6) Derecho a la credibilidad (Kreditfähigkeit, Xin Yong Quan) (cuatro artículos), y (7) Derecho a la privacidad (cuatro artículos). De acuerdo al artículo articulo 1 de esta parte, los derechos de la personalidad que pertenecen a una persona natural son los siguientes: (1) Derechos a la Vida y a la Salud, (2) Derecho al Nombre, (3) Derecho a la Imagen, (4) Derecho al Honor y a la Reputación, (5) Derecho a la Credibilidad (Kreditfähigkeit), y (6) Derecho a la Privacidad. Las personas jurídicas tienen diferentes derechos de la personalidad respecto de las personas naturales. Tienen solo tres tipos: derecho a la denominación, derecho al honor y a la reputación, y derecho a la credibilidad. Esto significa que las personas jurídicas no tienen derecho a la privacidad. En comparación con los otros derechos de la personalidad del Proyecto, el derecho a la credibilidad no nos parece tan familiar. Es posiblemente la primera vez que tal derecho ha sido dispuesto en un Proyecto de Código Civil. De acuerdo a la filosofía china, en la sociedad toda persona se presume creíble; de otra forma, sería imposible para los seres humanos vivir juntos en paz. En consecuencia, la credibilidad de un sujeto de derecho debe ser considerada como un derecho de la personalidad. El Proyecto no ha dado una definición de este derecho a la credibilidad, pero la opinión prevaleciente es que debe ser entendido como un derecho que necesariamente pertenece a cualquier individuo, al cual se corresponde un interés económico derivado de su capacidad apreciada por la Gemeinschaft (comunidad). WANG LIMING, MIN FA QIN QUAN XING WEI FA [DERECHO CIVIL: DERECHO DE DAÑOS] 299 (1993); YANG LIXIN, REN SHEN QUAN FA LUN [SOBRE LA LEY DE DERECHOS DE LA PERSONALIDAD] 698 (2001). En mi opinión, el derecho a la credibilidad se refiere a la garantía general que una persona puede ofrecer a otra en relación a su capacidad actual de hacer algo o de abstenerse de hacerlo. En relación con las disposiciones sobre el derecho a la credibilidad en el Proyecto de Código de 2006, la legislatura china parece obtener su inspiración de la Fair Credit Reporting Act de 1970, 15 U.S.C. \$\$ 1681-1681 (2006), y el paragráfo 824 del BGB (Peligro en el Crédito), la que dice: "(1) Una persona que falsamente declara o disemina un hecho que está calificado para poner en peligro el crédito de otra persona o causar otras desventajas a su sustento o progreso debe compensar al otro por el daño causado por esto, incluso si, aunque no sepa que el hecho es falso, debió haberlo sabido. (2) Una persona que hace una comunicación y es inconsciente de que es falsa no está obligada a pagar los daños si ella o el receptor de la comunicación tienen un interés justificado en esa comunicación.”. Bürgerliches Gesetzbuch [BGB] [Código Civil] $\$ 824$, disponible en http://www.gesetze-iminternet.de/englisch_bgb/; ver YANG LIXIN, REPORTE LEGISLATIVO, supra nota 57, en 398.

58 Wang Jiafu, Er Shi Yi Shi Ji Zhong Guo Min Fa De Fa Zhan [El Desarrollo del Derecho Civil Chino en el Siglo Veintiuno], 2003 FA XUE JIA [REVISTA DE JURISTAS] número 4, en 9; Wang Liming, supra nota 52, en 21; Wang Liming, Wo Guo Min Fa Dian Zhong Ren Ge Quan de Jian Gou [Construcción en la Protección de Derechos de la Personalidad en el Código Civil de la RPC], 2003 Fa Xue Jia [Revista de 
C. Debate sobre el Proyecto de Código Civil de 2002: ideas de ANTICODIFICACIÓN Y DECODIFICACIÓN EN CHINA

Desde la publicación del Proyecto de Código Civil en el año 2002, el debate sobre la codificación del Derecho Civil ha sido muy intenso en China. En la communis opinio, la codificación civil es urgentemente necesaria para la concreción del Imperio del Derecho, garantizando así su certeza. El Proyecto de Código Civil del año 2002 es un importante paso hacia ella. La mayoría de los partidarios de la codificación favoreció respecto del Proyecto de Código Civil del año 2002 la adopción de muchos conceptos e instituciones legales provenientes del common law, con la expectativa de que, de esa manera, el futuro Código Civil chino pudiere superar al Código de Napoleón y al BGB.

Sin embargo, algunos académicos sostienen que no es necesario codificar el Derecho Civil en la China de hoy, considerando la fuerte influencia del common law en el Derecho Civil chino, el papel expansivo de la interpretación judicial, la tendencia hacia la decodificación en Europa y, asimismo, el poco desarrollo de la investigación iuscivilista en China. ${ }^{59}$ Ciertos juristas incluso piensan que la tendencia en el desarrollo del Derecho Civil se está apartando de la codificación, porque un Código Civil es muy rígido subsumir y ser aplicado de inmediato respecto de nuevas relaciones jurídicas, como, por ejemplo, la propiedad virtual; de modo que es constantemente erosionado por las leyes especiales y el derecho consuetudinario ${ }^{60}$. En su opinión, China debiere abandonar la codificación y adoptar el derecho de precedentes ${ }^{61}$. Pero, dada la ausencia absoluta de una tradición en el derecho de precedentes a lo largo de la historia china y el limitado número de jueces bien preparados, la mayoría de los académicos del Derecho Civil se opone a esta idea de no codificación.

En cualquier caso, comparar las experiencias del resto del mundo es extremadamente importante para el legislador chino. Por esta razón, el 27 de marzo del 2003, el

Juristas] número 4, en 13; Yang Lixin, REPORTE LEGISLATIVO, supra nota 57, en 93. Sin embargo, algunos destacados académicos se han opuesto a la creación de una parte independiente denominada "Derechos de la Personalidad" en el Código Civil, dado que dichos derechos pertenecen solo a las personas naturales. Estos estiman que este tipo de derecho debiese estar protegido esencialmente por el Derecho Procesal más que por un derecho de carácter sustantivo como el Derecho Civil. Vid. Jiang Ping, Retrospectiva y Perspectiva, supra nota 39, en 20; Liang Huixing, supra nota 40, en 5.

59 Vid. Ma Junju, Man Tan Min Fa Zou Shi He Wo Guo Min Fa Dian De Zhi Ding [Discurso General sobre la Tendencia del Derecho Civil y la Codificación del Derecho Civil Chino], 2003 TSINGHUA FA XUE [REVISTA JURÍDICA DE TSINGHUA] número 3, en 340, 369; Li Kaiguo, Ping Min Fa Cao An De Jie Gou [Sobre el Sistema y la Estructura del Proyecto del Código Civil], 2003 XIAN DAI FA XUE [CIENCIA JURÍDICA MODERNA] número 4, en 19; Tu Yong Qiang \& Kang Na, Zhong Hu Ren Min Gong He Guo Min Fa Dian De Zhi Ding Ying Gai Huan Xing [Es Necesario Posponer la Promulgación del Código Civil de la RPC], en MING FA FA DIAN HUA, JIE FA DIAN HUA HE FAN FA DIAN HUA [CODIFICACIÓN, DECODIFICACIÓN Y ANTICODIFICACIÓN DEL DERECHO CIVIL] 585 (Zhang Lihong \& Gao Fuping eds., 2008) [en adelante CODIFICACIÓN, DECODIFICACIÓN]; Shao Shixing, Ying Dang Zhong Shi Wo Guo Min Fa Fa Dian Hua De Zhi Yue Xing Yin Su [Es Necesario Poner Atención a los Factores que Restringen la Codificación], en CODIFICATION, DECODIFICATION, supra, en 616.

${ }^{60}$ Xu Xuelu \& Liang Peng, Shi Dai Chao Liu-Fei Fadian Hua [Tendencia Moderna: No-Codificación], en CODIFICATION, DECODIFICATION, supra nota 59, en 574.

${ }^{61}$ Ibid. 
Comité Permanente del Congreso Popular Nacional chino organizó un simposio internacional sobre el Proyecto del Código Civil chino del año 2002. Decenas de prominentes académicos japoneses y chinos, estudiosos del Derecho Civil provenientes de más de diez universidades diferentes y de institutos de investigación en China y Japón, hicieron presentaciones en la conferencia. Los participantes divergieron significativamente en cuanto a la estructura sistemática del Código; la razonabilidad de separar la parte que refiere al Derecho de las Obligaciones en Contratos y Daños; el concepto de Derechos de la Personalidad y la necesidad de enmarcarlos en una parte independiente del Código; al igual que en cómo definir el sistema de los Derechos Reales ${ }^{62}$. Las mismas discusiones también aparecieron en una conferencia internacional de gran envergadura realizada en Shangai, en abril de 2005, bajo el título: "Codificación, Decodificación y Anticodificación del Derecho Civil”, organizada por el Centro de Investigación Europeo de Derecho Romano y el Centro de Investigación de Derecho Civil Chino de la Universidad de Ciencia Política y Derecho de China Oriental. Esta conferencia constituye el más significativo diálogo internacional hasta la fecha sobre la cuestión de si se debe o no

62 Vid. Yang Lixin, Zhong Guo Min Fa Dian Cao An Guo Ji Yan Tao Hui Ji Yao [Notas del Simposio Internacional sobre el Proyecto del Código Civil Chino], en MIN FA PAN JIE YUAN JIU YU SHI YONG [INVESTIGACIÓN SOBRE LOS CASOS DEL DERECHO CIVIL Y SU APLICACIÓN] 14362 (2004) (con discusión sobre las diferencias de opinión presentadas en el simposio). Aparte de las ideas sobre la estructura del futuro Código Civil chino, expresadas por los académicos chinos y descritas previamente en este artículo, supra notas 48-58, el destacado jurista japonés, profesor Eiichi Hoshino, de la Universidad de Tokio, sugirió que el legislador chino adoptase la estructura del Proyecto de Código Civil de Camboya preparado por los juristas japoneses, que está compuesto por una Parte General y una Parte Especial (subdividido en cinco partes: Personas, Derechos Reales, Garantía de las Obligaciones, Familia y Sucesión). Otro famoso académico de Derecho Civil, el profesor Zentarou Kitagawa, de la Universidad de Kioto, parecía estar a favor del actual modelo legislativo del Derecho Civil chino, aseverando que es apropiado exponer todos los conceptos e instituciones fundamentales en un Código Civil y dejar que las diferentes leyes especiales regulen en detalle lo concreto de las relaciones civiles, tal como los derechos reales, derechos de la personalidad, derechos del acreedor, etc. Algunos académicos se oponen a la posición adoptada por el Proyecto de Código Civil del año 2002, según el cual el Código Civil necesita dedicar una parte independiente a los derechos de la personalidad, argumentando que la protección de los derechos de la personalidad es solo una cuestión sobre la técnica de la codificación, y que no hace ninguna diferencia si es que estos se establecen en una parte independiente o no del Código Civil. La mayoría de los académicos en esta conferencia, guiados por el profesor Zentarou Kitagawa y el profesor Liang Huixing, criticaron con agudeza la ausencia de una Parte General de Obligaciones en el Proyecto de Código Civil del año 2002, afirmando que es problemático determinar cómo se regularán la negotiorum gestio y el enriquecimiento sin causa en un Código Civil sin una Parte General que verse sobre las Obligaciones. Los juristas que estaban de acuerdo con dicha omisión, por ejemplo, el profesor Yang Lixin, de la Universidad de Remin en Beijing, replicaron que el legislador chino podría adoptar la solución ofrecida por el Código Civil francés, calificando el negotiorum gestio y el enriquecimiento sin causa como cuasicontratos, o establecerlos en la Parte General del Código Civil. Respecto de los derechos reales, el profesor Sun Xianzhong, de la Academia Social Nacional en Beijing, piensa que los tipos de derechos reales en China necesitaban ser creados sobre la base de estudios de los derechos reales en el derecho consuetudinario, e insistió en la necesidad de la adopción del Abstraktionsprinzip del derecho alemán. Con respecto al Abstraktionsprinzip, muchos juristas, incluido el profesor Eiichi Hoshino, estaban en contra de la posición del profesor Sun Xianzhong. En la opinión de estos juristas, resulta muy complicado trasladar este principio a la propia práctica jurídica, y es suficiente para el legislador salvaguardar la transacción sobre los derechos reales y proteger los intereses de las partes construyendo un adecuado sistema registral de los derechos reales. 
codificar el Derecho Civil en China; con más de 160 profesores chinos de Derecho Civil procedentes de todas partes del país (incluyendo Taiwán) y dieciocho destacados profesores extranjeros provenientes de Alemania, Italia, Francia, Bélgica, España, Hungría, Corea y Argentina, quienes participaron o contribuyeron con sus trabajos ${ }^{63}$. Esta conferencia es digna de atención por la fuerte expresión de ideas sobre la decodificación y recodificación del Código Civil en Europa, así como de la no codificación del Derecho Civil en China. En particular, el distinguido académico italiano Natalino Irti presentó una carta abierta a los estudiosos del Derecho Civil y legisladores chinos en general, argumentando que el actual modelo legislativo del Derecho Civil chino, que se caracteriza por proveer algunos principios generales y abstractos iuscivilistas en un Código (o un estatuto fundamental correspondiente) y que deja para las diferentes leyes especiales el detalle normativo, puede ser una tendencia en el desarrollo legislativo del Derecho Civil en el mundo. Coincidiendo con esta idea, el autor del presente artículo estima que el apronte de China hacia la codificación será totalmente diferente de aquel tradicional del Derecho continental, y que para lograr el éxito con esta codificación es actualmente más importante y urgente para China formar juristas de Derecho Civil más calificados que elaborar un Código Civil ${ }^{64}$.

\section{LEY SOBRE DERECHOS REALES DE 2007}

Después de la promulgación de la Ley Unificada de Contratación, de 1999, y de la publicación del Proyecto de Código Civil, del año 2002, el legislador de China aceleró la elaboración de una Ley sobre Derechos Reales a fin de proveer las principales reglas para la protección de estos en una economía social de mercado. Siguiendo la tradición del Derecho continental, el legislador chino comenzó con su proyecto de Ley sobre Derechos Reales en 1993. El 16 de marzo del año 2007, la Ley sobre Derechos Reales de China fue promulgada por el Congreso Popular Nacional por un margen aplastante (2.799 votos a favor de un total de 2.889) ${ }^{65}$. Su promulgación sentó varios hitos en la historia legislativa china. Desde su primer proyecto, en 1993, hasta su

\footnotetext{
${ }^{63}$ Contribuyeron con sus trabajos a esta conferencia, por ejemplo, el profesor Rainer Schulze (Universidad de Münster, Alemania), el profesor Okko Behrends (Universidad de Göttingen, Alemania), el profesor Massimo Bianca (Universidad de La Sapienza, Italia), el profesor Natalino Irti (Universidad de La Sapienza, Italia), el profesor Giuseppe Gandolfi (Universidad de Pavia, Italia), la Profesora Maria Letizia Ruffini (Universidad de Milán, Italia), el profesor Alessio Zaccaria (Universidad de Verona, Italia), el profesor Stefano Troiano (Universidad de Verona, Italia), el profesor Jean-Louis Halpérin (Escuela Normal Superior de París), el profesor Betrand Fages (Universidad XII de París), el profesor Dirk Heirbaut (Universidad de Ghente, Bélgica), el profesor Gábor Hamza (Universidad de Budapest, Hungría), el profesor Byound Jo Choo (Universidad Nacional de Seúl, Corea), y la Profesora Esther Arroyo i Amayuelas (Universidad de Barcelona, España). Vid. Zhang Lihong, Xu [Prefacio] en CODIFICACIÓN y DECODIFICACIÓN, supra nota 59 , en 3 .

${ }^{64}$ Zhang Lihong, Min Fa Jie Fa Dian Hua He Zhonguo Min Fa Dian De Zhi Ding [Decodificación del Código Civil y el Proyecto del Futuro Código Civil de la RPC], 2006 FA XUE YUE KAN [BOLETÍN MENSUAL DE JURISPRUDENCIA] número 4, en 45.

${ }^{65}$ Ley sobre Derechos Reales (promulgada por el Congreso Popular Nacional Chino, 16 de marzo de 2007, efectiva desde el 1 de octubre de ese mismo año), LAWINFOCHINA (última visita el 30 de enero del año 2009).
} 
promulgación, en el 2007, su tramitación duró catorce años, transformándolo en el mayor período de tiempo que se haya necesitado para elaborar una ley en la historia de la RPC. Desde su tramitación inicial en el Congreso Popular Nacional, en 2002, sus proyectos fueron discutidos ocho veces en el Parlamento, marcando otro hito en la historia legislativa de la RPC. Esta ley tiene 247 artículos y seis partes, con la siguiente estructura: Parte I. Disposiciones Generales (arts. 1-38); Parte II. Propiedad (arts.39116); Parte III. Derechos de Usufructo (arts. 117-169): Parte IV. Derechos de Garantía de las Obligaciones (arts. 170-240); Parte V. Posesión (arts. 241-245; y Parte VI. Disposiciones Complementarias (arts. 246-247).

Esta ley tiene las siguientes características:

1. Es una ley sobre derechos reales socialista, que apunta a proteger la propiedad socialista, el interés público y las ideologías socialistas. Por ejemplo, clasifica la propiedad en estatal, colectiva y privada, pero comparado a la tradicional protección de la propiedad colectiva en el Proyecto de Código Civil del año 2002, destacan algunas nuevas ideas.

Siguiendo la enmienda constitucional del año 2004 sobre la protección de la propiedad privada, la Ley sobre Derechos Reales reconoce la igual protección de los derechos reales estatales, colectivos y privados. "La propiedad estatal, colectiva y privada serán protegidas por la ley. Está prohibido para cualquiera ocupar o destruir de cualquier forma la propiedad estatal, colectiva y privada" 66 .

La ley proporciona cuatro maneras diferentes en que el Estado puede ejercer el dominio, con la intención de prevenir o limitar la pérdida de la propiedad estatal: (1) El Consejo de Estado ejercita el dominio estatal en nombre del Estado en todos los recursos de los cuales el Estado es naturalmente dueño, como las minas, agua, mar, tierra estatal, etc. ${ }^{67}$; (2) el cuerpo público administrativo tiene el derecho de poseer, usar, otorgar usufructos, y disponer de los bienes muebles o los derechos reales que estén directamente bajo su control, de acuerdo con la ley o las regulaciones administrativas ${ }^{68}$; (3) una organización sin fines de lucro establecida por el Estado tiene el derecho a ocupar, usar, otorgar usufructos y disponer de los bienes muebles e inmuebles que estén directamente bajo su control, de acuerdo con la ley o las regulaciones administrativas ${ }^{69}$; y (4) en lo que se refieren las empresas en que existe inversión estatal, los gobiernos centrales o locales desempeñan el papel de inversionista, actuando como representantes del Estado en la titularidad del dominio equitativo sobre dichas empresas ${ }^{70}$.

2. La ley dispone expresamente que debe proporcionarse una razonable indemnización por cualquier expropiación o confiscación de la propiedad por el interés público $^{71}$.

\footnotetext{
66 Id. art. 4.

67 Id. art. 45.

${ }^{68}$ Id. art. 53

69 Id. art. 54

${ }^{70}$ Id. art. 55

${ }^{71}$ Id. arts. 42-44.
} 
Dado que la Constitución señala que la tierra pertenece solo al Estado o a las unidades colectivas, la Ley sobre Derechos Reales de 2007 proporciona algunos iura in re aliena de raigambre china concernientes al uso de la tierra por intereses privados, a saber: el derecho de contratar tierra rural $^{72}$, el derecho a usar tierra perteneciente al Estado para construir ${ }^{73} \mathrm{y}$, asimismo, el derecho para usar tierra colectiva para construir $^{74}$. Habiendo sido sancionados como iura in re aliena junto con las servidumbres, todos estos derechos no solo pueden prorrogarse al momento de su expiración, sino que también son transferibles entre particulares de acuerdo a los requisitos establecidos por la ley. De esta manera, el legislador chino apunta a hacer posible el uso de la tierra colectiva y estatal al sector privado, y, a su vez, a evitar el control de la propiedad estatal o colectiva de esta.

Con todo, a fin de proteger el interés estatal y colectivo, está prohibido dar en hipoteca tanto la propiedad de la tierra como el derecho de uso de la tierra colectiva (excepto si la ley dispone lo contrario), y, asimismo, el derecho de uso de cualquier entidad educacional, médica u otra que ataña al interés público ${ }^{75}$.

3. En términos de técnica legislativa, esta ley está modelada fuertemente por el Derecho alemán; aun cuando no adopta claramente el Abstraktionsprinzip en la transferencia de los derechos reales. Establece un sistema registral uniforme para los bienes inmuebles, ${ }^{76}$ disciplina las servidumbres ${ }^{77}$ y considera la naturaleza de la copropiedad como una mezcla entre la propiedad privada sobre un apartamento, la copropiedad de las cosas de uso común del respectivo edificio y el derecho a la administración común de dicho edificio por parte de todos los propietarios de sus apartamentos ${ }^{78}$. Además, califica la posesión como un hecho y a la vez como un derecho ${ }^{79}$ y protege la adquisición de la propiedad por el detentador de las cosas de buena $\mathrm{fe}^{80}$.

4. La ley también incluye algunas instituciones de la propiedad propias del common law. Por ejemplo, adopta el crédito hipotecario ${ }^{81}$ y la prenda flotante (floating charge $)^{82}$, y reconoce la práctica de hipotecar una propiedad que esté aún en construcción, tal como un edificio, un barco o un avión, e incluso futuros bienes muebles ${ }^{83}$.

\section{E. Crítica ACAdÉmica A la LeY SObRe Derechos ReAles de 2007}

Desde su promulgación, la Ley sobre Derechos Reales china ha sido duramente criticada en la academia china con respecto a los siguientes aspectos:

\footnotetext{
72 Id. arts. 124-134.

73 Id. arts. 135-154.

${ }^{74}$ Id. arts. $152-155$.

75 Id. art. 184.

76 Id. art. 10.

77 Id. arts. 156-169.

78 Id. art. 70.

79 Id. art. 241.

${ }^{80}$ Id. art. 106.

81 Id. art. 223.

82 Id. art. 228.

${ }^{83}$ Id. art. 180.
} 


\section{Sobre la protección de la propiedad estatal}

Se ha argumentado que la Ley sobre Derechos Reales debiere reforzar la posición de liderazgo de la propiedad pública. Lo anterior, porque la posición del legislador en cuanto a proteger la propiedad estatal, colectiva y privada equitativamente, está poniendo fin al socialismo en China y, por lo tanto, acelerando el proceso de pérdida de la propiedad estatal y el desarrollo del capitalismo. ${ }^{84}$ En consecuencia, para prevenir la pérdida de la propiedad estatal, se debería aumentar la investigación dedicada al Código Civil Ruso y otros códigos civiles socialistas respecto de aquella que ha versado sobre los códigos civiles de países capitalistas. Esta posición ha sido criticada por la mayoría de los académicos del Derecho Civil en China ${ }^{85}$.

\section{Sobre la posibilidad de comercializar el derecho a usar predios rústicos para la habitación}

La Ley sobre Derechos Reales no dispone nada respecto a la adquisición, ejercicio o extinción del derecho a usar predios rústicos para habitación, permitiendo que ello sea regulado por la Ley sobre Administración de la Tierra, otras leyes aplicables y la política estatal aplicable ${ }^{86}$. En concordancia con la Ley de Administración de la Tierra de $2007^{87}$ y la Ley de Garantías de $1995^{88}$, el titular de este derecho no podía transferirlo a otras personas ni constituir una hipoteca sobre él. Al prohibir la transferencia del derecho a

${ }^{84}$ El 12 de agosto del año 2005, el profesor Gong Xiantian de la Universidad de Beijing presentó una carta abierta titulada: "Un Proyecto de la Ley sobre Derechos Reales en contra de un capítulo de la Constitución y de los principios fundamentales del Socialismo" ante el Comité Permanente del Congreso Popular Nacional chino. En este, él asevera que el proyecto del año 2005 insinúa pensamientos en favor de la privatización de bienes públicos, la protección de la propiedad privada y el desarrollo del capitalismo porque ha sido contrario al principio constitucional de la "No Violación de la Propiedad Socialista y Pública", y tampoco ha sido la solución correcta para prevenir la pérdida de los bienes públicos. De esta manera, él arguye que el proyecto de la Ley sobre Derechos Reales representa un paso atrás y se opone fuertemente a su promulgación.

La mayoría de los académicos del derecho civil criticaron la oposición del profesor Gong Xiantian al proyecto de la Ley sobre Derechos Reales. De hecho, este debate sobre la postura del profesor Gong Xiantian demuestra la divergencia existente en el método de la Reforma Socialista china entre los intelectuales actuales de ese país. Vid. Jiang Ping, Jian Chi Shen Me Yang De She Hui Zhu Yi [¿̨En qué tipo de Socialismo debemos insistir?], 2007 YANGHUANG CHUNQIU [Primavera \& Invierno China] número 4 , en 29.

${ }^{85}$ Yu Nengbin, Wo Guo Wu Quan Li Fa Jie Jian De Li Xing Xuan Ze He Fan Shi [Elección Racional y Reflexiones sobre la Legislación en la Ley sobre Derechos Reales en China], 2006 HUAN QIU FA LÜ PING LUN [REVISTA DE DERECHO GLOBAL] número 1, en 22.

${ }^{86}$ Ley de Derechos Reales, art. 153 (promulgada por el Congreso Popular Nacional chino, 16 de marzo de 2007, vigente desde 1 de octubre de 2007), LAWINFOCHINA (última visita el 30 de enero de 2009).

87 Ley de Administración de Suelos, art. 62 (promulgada como modificación por el Congreso Popular Nacional chino, 29 de agosto de 1998, vigente desde 1 de enero de 1999, enmendada el 28 de agosto de 2004), LAWINFOCHINA (última visita el 30 de enero de 2009).

${ }^{88}$ Ley de Garantías, art. 37 (adoptada por el Congreso Popular Nacional chino, 30 de junio de 1995, vigente desde 1 de octubre de 1995), LAWINFOCHINA (última visita el 30 de enero de 2009).

89 Guo Mingrui, Guan Yu Zhai Ji Di Shi Yong Quan De Li Fa Jian Yi [Sugerencias Respecto a la Legislación sobre el Derecho a Usar Predios Rústicos para la Habitación], 2007 FA XUE LUN TAN [FORO LEGAL] número 1, en 24. 
usar predios rústicos para la habitación, el legislador chino intentó garantizar a todo campesino su casa propia y proteger a China del alto riesgo de agitación social creado por la indigencia.

Ahora bien, esta situación hacía imposible atribuir un valor pecuniario a este derecho. Por lo que algunos juristas habían planteado que debería permitirse que este derecho se venda, intercambie o hipoteque libremente si tal garantía es otorgada a favor de quien tiene suficiente solvencia y por quien es dueño ${ }^{89}$.

Es de notar que en octubre de 2008 el Gobierno central chino decidió hacer transferible el derecho de usar predios rústicos para la habitación, permitiendo plenamente su contratación, adquisición, venta y permuta. Actualmente, cómo construir un sistema eficiente y seguro para su transferencia es una materia clave de investigación para el legislador y los juristas $\operatorname{chinos}^{90}$.

\section{Sobre la usucapión [prescripción adquisitiva extraordinaria]}

La Ley sobre Derechos Reales de 2007 suprimió la institución de la usucapión [prescripción adquisitiva extraordinaria], la cual había sido establecida en el Proyecto de Código Civil de 2002. Algunos importantes académicos explican que dicha institución es impracticable en el Derecho continental moderno, debido a la expansión de la institución de la "adquisición del dominio por el poseedor de buena fe", y es contraria a la moral china, de acuerdo a la cual quien encuentre una cosa perdida debe devolverla a su dueño ${ }^{91}$.

En opinión de muchos académicos del Derecho Civil, esta posición no es viable, pues dificulta la determinación del dominio de las cosas abandonadas, como por ejemplo, el dominio de la basura reciclable ${ }^{92}$.

\section{Sobre cómo definir el interés público}

Existe también un debate respecto a cómo definir el interés público y cómo cuantificar una indemnización razonable en caso de requisición o expropiación de la propiedad. La mayoría de los académicos piensa que serían necesarias una ley administrativa especial y la interpretación judicial para resolver el problema ${ }^{93}$. El legislador

${ }^{90}$ Ver LU XIAOCHUAN, ZHAI JU DI FA LÜ WEN TI [CUESTIONES RELATIVAS AL DERECHO DE HABITACIÓN SOBRE PREDIOS RÚSTICOS] (2008).

${ }^{91}$ DONG XUELI, WU QUAN FA YAN JIU [Estudios sobre la Ley sobre Derechos Reales] 286 (2007).

${ }^{92}$ Li Jianhua, Peng Chengxin \& Yang Daixiong, Zhong Guo Wu Quan Fa Li Fa Ji Shu Ruo Gan Qu Exian de Fen Xi Yu Wan Shan [Análisis sobre Varios Defectos de Técnica Legislativa en la Ley sobre Derechos Reales], 2007 DANG DAI FAXUE [JURISPRUDENCIA CONTEMPORÁNEA] número 4, en 139.

${ }^{93}$ Ya que es imposible demarcar clara y oportunamente la frontera del interés público, debido a la ambigüedad y elasticidad del concepto, siguiendo la sugerencia de los académicos, el legislador chino optó por disponer, de un modo general y sintético, que podía realizarse una confiscación o requisición si ello fuere necesario para proteger el interés público. Es probable que más adelante se establezca un procedimiento administrativo detallado para delimitar del interés público en casos concretos, al igual que los respectivos procedimientos administrativos para eventuales solicitudes o reclamaciones; atribuyendo finalmente al juez la facultad de decidir, en definitiva, si una confiscación o requisición concreta ha sido conforme al interés público. Ver Hu Honggao, Lun Gong Gong Li Yi De Fa Lü Jie Ding [Sobre el Concepto Legal de Interés Público], 2008 ZHONG GUO FA XUE [JURISPRUDENCIA CHINA] nú- 
chino ha planeado aprobar una ley administrativa especial en 2009, llamada Cheng Shi Chai Qian Tiao Li [Regulación de la Demolición de Bienes Raíces Urbanos], con el fin de regular este procedimiento administrativo expropiatorio.

\section{Sobre el carácter gratuito de la restitución de una cosa perdida}

La Ley sobre Derechos Reales de 2007 dispone que en caso de restitución de una cosa perdida, el dueño debe soportar únicamente los gastos de conservación ${ }^{94}$, mientras la persona que la ha encontrado o restituido no tiene derecho a recibir el pago de premio alguno por parte del dueño, ni adquiere el dominio de la cosa si nadie la reclama ${ }^{95}$. El legislador justifica estas disposiciones diciendo que ellas son conformes a los valores tradicionales de China y del socialismo. La visión opuesta es que dichas disposiciones crean incentivos para no devolver la cosa perdida, y que en lugar de esta regulación, el dueño debería estar obligado a pagar a quien encontró la cosa una tarifa correspondiente a cierto porcentaje del valor de la cosa -por ejemplo, el veinte por ciento- ${ }^{96}$.

\section{Sobre el concepto de derecho real y la naturaleza de la Ley sobre Derechos Reales}

Algunos académicos sugieren abandonar el concepto mismo de "derecho real" en el Derecho chino y consideran que la promulgación de esta Ley es una decisión legislativa contraria a la tendencia mundial hacia el progresivo desarrollo del property law ${ }^{97}$; basándose para ello en los dos argumentos siguientes.

Primero, el concepto moderno de "derecho real" (Sachenrecht) es solo un producto de la pandectística alemana del siglo XIX. En dicho periodo, la sociedad estaba caracterizada por la agricultura y los principales recursos económicos estaban representados por propiedades tangibles (principalmente cosas inmuebles). Los principales recursos económicos de la sociedad industrial o postindustrial de hoy en día son, en cambio, cosas intangibles, tales como la propiedad intelectual y virtual; de tal manera que no existe la necesidad de elaborar una ley relativa a derechos reales.

mero 4, en 64; Wang Liming, Wu Quan Fa Shi Shi Si Da Dong Xiang [Cuatro Tendencias en la Implementación de la Ley sobre Derechos Reales], http://www.dffy.com/faxuejieti/ms/200804/ 20080403114054.htm (última visita el 30 de marzo de 2009). Estos consejeros están basados en la experiencia legislativa de protección del interés público en casos de confiscación o requisición en Estados Unidos, Francia, Canadá, Australia, Holanda, etc.

${ }^{4}$ Ley de derechos reales, art. 112 (promulgada por el Congreso Popular Nacional chino, 16 de marzo de 2007, vigente desde 1 de octubre de 2007), LAWINFOCHINA (última visita el 30 de enero de 2009).

95 Id. arts. 109 y 113.

96 Ver Qiao Jiao, You Heng Chan Zhe You Heng Xin [Quien Tenga Derechos de Propiedad Claros, Tiene Una Voluntad Consistente], 2005 CHANG QUAN DAO KANG [Guía de los Derechos de Propiedad], número 8, en 14 .

97 Xie Zengyi \& Ran Hao, Cai Chan Fa Yu Wu Quan Fa Chan Bi Jiao “Wu Quan Fa Cao An” [Estudios Comparativos de Derecho de Propiedad y de los Derechos Reales - Comentarios sobre el Proyecto a la Ley sobre Derechos Reales], 2006 HUAN QIU FA LÜ PING LUN [REVISTA DE DERECHO GLOBAL] número 1 , en 9 . 
Segundo, es difícil redefinir el concepto de "derecho real". La distinción entre derechos reales y personales es tan ambigua que ni el Derecho Romano ni el Código Civil francés crean (o adoptan) tal concepto de "derecho real". El sistema alemán de derechos reales - por ejemplo, el principio de Abstraktionsprinzip- fue formado y desarrollado en un contexto social y económico sumamente especial, el cual era sustancialmente diferente del contexto de la China actual. En síntesis, el concepto de derecho real es anticuado y obsoleto, de manera que debiere ser reemplazado por el concepto del common law de "property right" 98 . La adopción de la floating charge, el trust y el financiamiento de proyectos a largo plazo (Project finance) en el Derecho continental, hacen imposible que dicho sistema defina claramente lo que habría que entender hoy por derecho real. Por lo tanto, es poco útil estudiar el Derecho alemán en relación con los derechos reales. En cambio, ha llegado a ser más importante estudiar el tratamiento del common law relativo a la propiedad, debido a su flexibilidad; y, asimismo, el Derecho ruso, debido a su contexto social y experiencia histórica similares a la de China ${ }^{99}$.

Adicionalmente, en opinión de algunos importantísimos académicos del Derecho Público ${ }^{100}$, el verdadero Derecho relativo a los derechos reales no es solo el Privado, sino también aquel, pues establece el proceso administrativo y los medios de protección y transferencia de los derechos reales. Por ello, es incorrecto definir la Ley sobre Derechos Reales de 2007 como Derecho Privado: un sistema moderno y científico de derechos reales no debiera ser establecido únicamente en un Código Civil.

\section{F. Los Últimos Avances en la Elaboración de la LeY de Daños de CHINA}

Luego de aprobar la Ley sobre Derechos Reales en 2007, el Congreso chino se dio la tarea, en la que persevera hasta hoy, de promulgar una Ley especial sobre Daños. De manera similar a lo ocurrido con la unificación del Derecho de Contratos, en 1999, los redactores de la Ley de Daños están intentando reunir todas las normas existentes ${ }^{101}$ y eliminar las antinomias entre ellas.

\footnotetext{
98 Ver id. en 38; Chen Taihe, Zhang Haimin \& Xu Liuxin, Wu Quan Fa Ying Dang Huan Xing Shen Xing [Es Necesario Posponer la Promulgación de la Ley sobre Derechos Reales], 2006 HUAN QIU FA LÜ PING LUN [REVISTA DE DERECHO GLOBAL], número 1, en 59.

${ }^{99}$ Yu Nengbin, supra nota 85, en 22.

${ }^{100}$ Ver, por todos, a Tong Zhiwei, Wu Quan Fa Li Fa Guo Cheng Ru He Zuo Qia Dang Ping Jia [Cómo Evaluar el Proceso Legislativo de la Ley sobre Derechos Reales], 2007 FA XUE YUE KAN [BOLETÍN MENSUAL DE JURISPRUDENCIA] número 4, en 27.

101 Actualmente, el estatuto jurídico de la responsabilidad extracontractual está constituido por: los PGDC de 1986; las Opiniones de la Corte Popular Suprema Sobre Varias Cuestiones Relativas a la Implantación de los Principios Generales del Derecho Civil de 1988 (26 de enero de 1988), LAWINFOCHINA (última visita el 30 de enero de 2009); tres interpretaciones judiciales en materia de Daños, de 1998, 2001 y 2003 ; y varias otras leyes y regulaciones administrativas. Véanse, por ejemplo, la Ley de Calidad de Productos (promulgada como modificación por el Congreso Popular Nacional Chino, el 8 de julio de 2000, vigente desde 1 de septiembre de 1993), LAWINFOCHINA (última visita el 30 de enero de 2009); la Ley de Responsabilidad del Estado (promulgada por el Congreso Popular Nacional chino, el 12 de mayo de 1994, vigente desde 1 de enero de 1995), LAWINFOCHINA (última visita el 30 de enero de 2009); la Regulación sobre el Manejo de los Accidentes Médicos (promulgada por el Consejo de Estado, 20 de febrero de
} 
La parte relativa a los Daños del Proyecto de Código Civil de 2002 constituye el principal documento de trabajo del Congreso para esta futura legislación. Esta sede del Proyecto consta de sesenta y ocho artículos y diez capítulos: I: Disposiciones generales (arts. 1-7); II. Demandas de indemnización (arts. 8-20); III. Causales de justificación para la exoneración de la responsabilidad (arts. 21-24); IV. Responsabilidad derivada de accidentes de vehículos motorizados (arts. 25-30); V. Responsabilidad por daño medioambiental (arts. 31-34); VI. Responsabilidad por productos (arts. 35-40); VII. Responsabilidad derivada de trabajos altamente peligrosos (arts. 41-52); VIII. Responsabilidad por daños a las personas causados por animales (arts. 53-54); IX. Responsabilidad por daños causados a personas por objetos caídos de edificios (arts. 55-60); y X. Disposiciones especiales respecto al obligado a soportar los daños (arts. 61-68). Durante la elaboración de la Ley de Daños, el legislador chino no solo usó el mencionado documento de trabajo, sino también las recomendaciones relativas a esta ley de algunos académicos de Derecho Civil ${ }^{102}$. Además, el legislador chino llevó a cabo una importante investigación respecto de los efectos de la aplicación de la legislación actual. En otras palabras, los proyectos de leyes de responsabilidad extracontractual fueron el producto de estudios relativos a las teorías de la responsabilidad extracontractual en el Derecho continental y en el common law, así como la indagación en torno a la experiencia de los jueces chinos en la aplicación práctica de las normas existentes en esta materia.

Después de seis años de trabajo en la elaboración de los proyectos, y de muchas consultas a los académicos de Derecho Civil, el Comité de Asuntos Legislativos de Congreso Popular Nacional terminó una nueva versión del proyecto de la Ley de Daños en septiembre de 2008; revisándola, posteriormente, en octubre y diciembre del mismo año. Al hilo de esto, fue así como la más reciente versión del proyecto -es decir, la segunda versión oficial- fue enviada al actual Comité del Congreso Popular Nacional Chino en diciembre de $2008^{103}$; transformándose en objeto de un gran debate, tanto al

2002, vigente desde 1 de septiembre de 2002), LAWINFOCHINA (última visita el 30 de enero de 2009); la Regulación sobre Seguros de Accidentes del Laborales (promulgada por el Consejo de Estado el 27 de abril de 2003, vigente desde 1 de enero de 2004), LAWINFOCHINA (última visita el 30 de enero de 2009); la Ley sobre Seguridad del Tráfico en Carreteras (promulgada como modificación por el Congreso Popular Nacional Chino, 29 de diciembre de 2007, vigente desde 1 de mayo de 2004), LAWINFOCHINA (última visita el 30 de enero de 2009), así como un gran número de leyes y regulaciones regionales sobre Daños.

102 Hasta ahora, los informes consultivos sobre la Ley de Daños preparados por académicos de Derecho Civil, son los siguientes: WANG LIMING, ZHONG GUO MIN FA DIAN XUE ZE JIAN YI GAO JI LI FA LI YOU: QIN QUAN XING WEI FA BIAN [INFORME CONSULTIVO SOBRE EL CÓDIGO CIVIL CHINO PREPARADO POR ACADÉMICOS: PARTE SOBRE DERECHO DE DAÑOS] (2003); LIANG HUIXING, MIN FA DIAN JAN YI GAO [INFORME CONSULTIVO DEL CÓDIGO CIVIL CHINO] 305-28 (2003); XU GUODONG, LÜ SE MIN FA DIAN CAO AN [PROYECTO SOBRE EL CÓDIGO CIVIL VERDE] 705-25 (2004); YANG LIXIN, ZHONG HUA REN MIN GONG HE GUO QIN QUAN XING WEI JIAN YI GAO [INFORME CONSULTIVO SOBRE DERECHO DE DAÑOS DE LA RPC] (2007).

${ }^{103}$ Véase Bai Long, Qin Quan Fa Cao An Guan Zhu Qin Quan Xin Lei Xing: Qin Quan Wang Zhan Xu Cheng Dan Ze Ren [El Proyecto de Ley de Daños Busca Nuevas Formas de Daños: Sitios Web Debieren ser Responsables por los Daños online], REN MIN RI BAO [DIARIO POPULAR], 24 de diciembre de 2008, http://www.ce.cn/xwzx/gnsz/gdxw/200812/24/t20081224_17765994.shtml. 
interior del Congreso Popular Nacional como entre los juristas. La promulgación de esta Ley de Daños está programada para el año 2010.

\section{G. La Última Versión del Proyecto de ley de Daños: CONTENido y CARACTERÍSTICAS \\ Como mencionábamos anteriormente, la versión más reciente del proyecto de Ley} de Daños fue terminado en diciembre del año 2008; y es significativamente diferente de lo establecido respecto de los Daños en el Proyecto del Código Civil del año 2002. Está compuesto de ochenta y ocho artículos divididos en doce capítulos: I. Disposiciones generales (arts. 1-6); II. Elementos constitutivos de la responsabilidad por daños y sus factores de atribución (arts. 7-25); III. Causales de justificación para la exoneración de la responsabilidad por daños o para sus mitigaciones (arts. 26-30); IV. Disposiciones especiales sobre el titular de la responsabilidad (arts. 31-38), que conciernen la atribución de responsabilidad a personas distintas del causante del daño; V. Responsabilidad por productos (arts. 39-45); VI. Responsabilidad por daños resultantes de accidentes relativos a vehículos motorizados (arts. 46-52); VII. Responsabilidad por daños resultantes de tratamientos médicos (arts. 53-66); VIII. Responsabilidad por daño ambiental (arts. 67-71); IX. Responsabilidad por daños resultante de trabajos altamente peligrosos (art. 72); X. Responsabilidad por daños a las personas originados por animales (arts. 7881); XI. Responsabilidad por daños a las personas resultantes de objetos subterráneos o aquellos que han caído de edificios (arts. 82-87); y, XII. Disposiciones complementarias (art. 88).

Este proyecto se caracteriza por mezclar elementos tanto del sistema de Derecho continental como del sistema del common law. Sigue el modelo legislativo tradicional del Derecho continental, estableciendo algunas cláusulas generales sobre daños y luego algunas cláusulas específicas relativas a daños especiales (o típicos). Sin embargo, el contenido de algunas de estas disposiciones sobre daños especiales proviene directamente del common law.

Las cláusulas generales de este proyecto constituyen sus tres primeros capítulos (arts. 1-30) y comprenden el principio de atribución de la responsabilidad por daños, la legitimación activa de la acción de daños, los modos de extinción de la responsabilidad por daños, la distribución de la responsabilidad y las causales de exoneración de la responsabilidad ${ }^{104}$. En principio, estas cláusulas generales son aplicables a toda clase de daños, excepto aquellos especiales establecidos en algunas cláusulas específicas. Desde el capítulo 4 al capítulo 11 (arts. 31-87) el proyecto establece doce clases de daños típicos: los daños provenientes de accidentes vehiculares; los daños provenientes de contaminación ambiental; los daños causados por productos defectuosos; los daños resultantes de trabajos u objetos altamente peligrosos; los daños provenientes de accidentes médicos; los daños causados por animales; los daños por objetos subterráneos o caídos de edificios; los daños por la conducta de los pupilos; los daños por la conducta in officis de una

${ }^{104}$ Diciembre de 2008, proyecto de Ley de Daños, arts. 1-30. 
persona natural en representación de una persona jurídica; los daños por un proveedor de internet; los daños causados por la negligencia en la protección de la seguridad del tránsito (Verkehrssicherungspflichten); y los daños por la negligencia de una escuela en relación al deber de cuidado respecto de los niños. En cuanto a la Typenzwang (formulación típica) de estos daños especiales, el legislador ha considerado principalmente la experiencia correlativa del Derecho continental, pero también la del common law; por ejemplo, en la responsabilidad por daños resultantes de la contaminación ambiental, en los productos defectuosos, en los accidentes médicos y en los daños provenientes de trabajos u objetos altamente peligrosos.

El proyecto de Ley de Daños también incluye el bien conocido principio de la responsabilidad por culpa, proveniente del Derecho Romano y del Derecho continental moderno. Esta aparece como el principal factor de atribución, tanto para la determinación de la responsabilidad extracontractual del ofensor ${ }^{105}$, como para el caso en que la responsabilidad por daños entre las partes contractuales ${ }^{106}$ deba ser distribuida -a saber, aplicando la llamada compensación de culpas- entre ambos causantes del daño ${ }^{107}$ de acuerdo al grado de su culpa. Siguiendo la experiencia histórica del Derecho continental moderno, el artículo 7 expresamente estipula la presunción de culpa -es decir, la inversión de la carga de la prueba-, señalando que "en los casos en que según la ley, se presume la culpa, el causante del daño deberá asumir la responsabilidad a menos que pruebe su ausencia"108. El proyecto dispone de manera explícita la aplicación de la presunción de culpa para algunos daños especiales. Por ejemplo, establece que "en el caso de que animales domésticos causen daños a las personas, el amo deberá responder por los perjuicios. Sin embargo, si se prueba que los daños son causa de la negligencia grave de las personas dañadas, se eximirá o mitigará la responsabilidad del amo"109. La misma regla se aplica a aquellos casos de daños a las personas resultantes de objetos subterráneos o de aquellos caídos de edificios ${ }^{110}$, así como a los daños provenientes de tratamientos médicos ${ }^{111}$.

Sin embargo, bajo la influencia de la teoría de la responsabilidad sin culpa (strict liability) del common law, el proyecto en estudio establece que "en el caso en que la ley establezca que una determinada persona debe soportar la responsabilidad sin requerir la existencia de culpa por parte de ella, dicha persona deberá responder"112 y "en el caso de los daños resultantes de actividades altamente peligrosas, el causante del daño será responsable incluso si no es culpable, salvo que existan causales de justificación que lo eximan de responsabilidad según lo establecido por la ley"113. Este tipo de norma sobre

\footnotetext{
105 Id. art. 7.

106 Id. art. 26.

107 Id. art. 16.

108 Id. art. 7.

109 Id. art. 78.

110 Id. art. 82.

${ }^{111}$ Id. art. 58.

112 Id. art. 8.

113 Id. art. 72.
} 
la atribución de la responsabilidad por daños sin culpa también existe en los PGDC ${ }^{114}$, para el caso de los daños ambientales ${ }^{115}$ y de los daños por productos defectuosos ${ }^{116}$. Estas disposiciones del proyecto sobre responsabilidad sin culpa y sobre responsabilidad respecto de los productos defectuosos provienen directamente de la sección 402A del American Restatement (Second) of Torts ${ }^{117}$.

Respecto a la atribución de responsabilidad a personas distintas del causante del daño, este proyecto incorpora tanto la experiencia del Derecho continental como la del common law. Adopta la solución tradicional del Derecho continental sobre la atribución de responsabilidad por daños de los pupilos, disponiendo que quien tiene la custodia será responsable de los daños de los pupilos bajo su cuidado, y que dicha responsabilidad puede ser mitigada si quien tiene la custodia ha cumplido sus deberes de cuidado ${ }^{118}$. Se recibe la llamada teoría del "deber de protección de la seguridad de la transacción" (Verkehrssicherungspflichten) del Derecho alemán, disponiendo que "los gerentes de hoteles, restaurantes, tiendas, bancos e instalaciones de esparcimiento serán responsables de los daños causados a las personas que se encuentren en dichos lugares, en el caso de que no hayan realizado sus deberes para la protección de la seguridad de la transacción"119. Por otra parte, el proyecto también sigue la famosa teoría de "la responsabilidad por actos de terceros" o "Vicarious liability" del Derecho estadounidense, estableciendo que

114 PGDC arts. 123-124 (promulgados por el Comité Permanente del Congreso Nacional Popular Chino, 12 de abril de 1986, efectivos el 1 de enero de 1987), LAWINFOCHINA (última visita el 30 de enero de 2009). El artículo 123 de los PGDC establece: "Si cualquier persona causa daño a otras por realizar actividades que son altamente peligrosas para el entorno, como operaciones llevadas a cabo a grandes alturas sobre el suelo, o aquellas que involucren alta presión, alto voltaje, combustibles, explosivos, sustancias altamente tóxicas o radioactivas o medios de transporte altamente veloces, dicha persona será civilmente responsable; sin embargo, si puede ser probado que el daño fue causado deliberadamente por la víctima, no deberá responder". El artículo 124 de los PGDC establece que "toda persona que contamine el ambiente y cause daño a otros en violación de normas estatales para la protección y prevención de la contaminación será responsable civilmente de acuerdo a la ley”.

115 diciembre de 2008 Proyecto de Ley de Daños, nota supra 104, art. 67 ("El emisor de contaminación será responsable si la contaminación causa daños a otras personas, salvo que existan causales de exoneración de responsabilidad establecidas por la ley").

116 Id. art. 39 ("El productor será responsable en caso de que el producto defectuoso cause daños a otras personas, excepto si puede probar la existencia de la siguiente situación: (1) los productos no han sido comercializados; (2) inexistencia de defectos al momento de la comercialización del producto; (3) al momento de su comercialización los defectos de los productos no pueden ser descubiertos, debido a las limitaciones de la tecnología").

117 RESTATEMENT (SECOND) OF TORTS $\$$ 402A (1965). Varios libros sobre el American Restatement of Torts han sido traducidos al chino y se han convertido en una importante referencia para el legislador chino y los académicos del Derecho. Por ejemplo, QIN QUAN FA CHONG SHU DI SAN BAN [RESTATEMENT (THIRD) OF TORTS: PRODUCT LIABILITY] (Xiao Yongping, Jia Lefang y Wang Xue Fei trad., 2006); QING QUAN XING WEI FA CHONG SHU-GANGYAO [A CONCISE RESTATEMENT OF TORTS] (Chuanyi trad., 2006). También ha sido traducido al chino, VINCENT R. JOHNSON, STUDIES IN AMERICAN TORT LAW (1999). En China, muchos trabajos sobre la Responsabilidad por Daños en los Estados Unidos han sido reimpresos y publicados en inglés. Véase, por ejemplo, EDWARD J. KIONKA, TORTS (Falu Press 1999) (1993).

118 Diciembre de 2008, Proyecto de Ley de Daños, nota supra 104, art. 31.

${ }^{119}$ Vid. id. art. 35. 
"las unidades que contraten empleados serán responsables por los daños causados por estos durando su trabajo in officis" 120 y "los institutos médicos serán responsables de la compensación de los daños causados con culpa por sus médicos empleados"121.

Es notable que los derechos del paciente a la información, los cuales fueron introducidos por el Derecho de Daños norteamericano y se componen del derecho al consentimiento informado y otros derechos a la información en relación a tratamientos médicos, también estén protegidos y regulados detalladamente en la última versión del proyecto de Ley de Daños de China. El artículo 55 de este proyecto dispone:

"Los médicos deben informar al paciente de su estado de salud y del eventual alcance del tratamiento médico, para el caso en que actúen en el contexto de una actividad clínica normal. En caso de necesitar una operación y un tratamiento o examen en circunstancias especiales, deberán obtener el correspondiente y previo consentimiento del paciente por escrito después de haberle informado sobre su condición de salud, el tratamiento médico y sus riesgos, así como algunas soluciones médicas alternativas. En caso de ser inapropiado otorgarle dicha información directamente al paciente, los médicos informarán a sus parientes más cercanos y obtendrán el consentimiento previo por escrito respecto del tratamiento médico. Si hay negligencia en la realización de estas obligaciones y daños como consecuencia, los médicos serán responsables de la indemnización de los perjuicios".

Atribuyéndole importancia a la protección de los derechos de los pacientes, los redactores del proyecto de Ley de Daños de China dedicaron el capítulo 7, con catorce artículos, a regular los daños derivados de tratamientos médicos o de las medicinas.

\section{H. Los Debates actuales SObre El Derecho De DaÑos}

Aunque este último proyecto de Ley de Daños de China todavía no ha sido puesto a disposición del público, los académicos chinos de Derecho Civil están dedicando gran parte de sus investigaciones a determinar la mejor manera de redactarlo. Los debates sobre responsabilidad por daños comprenden los siguientes temas.

\section{Sobre el nombre y la naturaleza del Derecho de Daños}

La opinión mayoritaria afirma que el Derecho de Daños apunta a regular la responsabilidad de los ofensores y a proporcionar las correspondientes acciones indemnizatorias ${ }^{122}$. Y dado que la naturaleza del Derecho de Daños arranca de la responsabilidad del ofensor, la futura Ley de Daños de China debiere ser llamada "Ley de Responsabilidad por Daños de la República Popular de China (RPC)”. Esta idea fue aceptada por el legislador en su más reciente proyecto, en el cual la Ley de Daños es llamada "Ley de Responsabilidad por Daños”. Sin embargo, algunos académicos piensan que el Derecho

\footnotetext{
120 Id. art. 33.

121 Id. art. 54.

122 Vid. Wang Liming, Lun Wo Guo Qing Quan Ze Ren Fa De Ti Xi Gou Jian [Sobre la construcción del sistema chino de Responsabilidad por Daños], 2008 ZHONG GUO FA XUE [CIENCIA JURÍDICA CHINA] número 4, en 4.
} 
de Daños tiene como función proteger los derechos civiles de la víctima, de modo que su naturaleza es la de una acción civil [fundada en el daño] y, por lo tanto, es más apropiado el nombre "Ley de Daños" que "Ley de Responsabilidad por Daños" 123.

\section{Sobre cómo establecer las cláusulas generales de la Ley de Daños}

El legislador y la mayoría de los académicos de Derecho Civil están de acuerdo en que la futura Ley de Daños de China necesita algunas cláusulas generales sobre la materia, similares a aquellas establecidas por todos los códigos civiles de los países con sistemas continentales de Derecho. Sin embargo, respecto de cómo exponer las cláusulas generales hay varias visiones divergentes.

Algunos académicos sugieren que las cláusulas generales deberían enumerar todos los tipos de derechos civiles o intereses protegidos por la ley, de cuya violación resulte la responsabilidad, adoptando así el modelo alemán establecido en el BGB, en sus parágrafos 823 y $826 .{ }^{124}$ De esta forma, sería claro para todas las materias civiles qué tipos de derechos están protegidos por la Ley de Daños. La versión precedente al último proyecto, es decir, la versión de octubre del año 2008, aceptó esta idea ${ }^{125}$.

Sin embargo, si seguimos el ejemplo de 1986 de los PGDC ${ }^{126}$, otros académicos se inclinan por exponer solo cláusulas generales respecto de la "responsabilidad por culpa”, sin especificar de manera típica los derechos civiles o intereses protegidos por la Ley de Daños; es decir, estableciendo de un modo general que una persona que intencional o negligentemente cause daño a otras personas será responsable de indem-

123 Vid. Zhu Wei, Qing Quan Ze Ren Fa Cao An Er Ci Shen Yi Gao Zhuan Jia Yan Tao Hui Zong Shu [Informe de la Conferencia sobre la Segunda Versión del Proyecto de Ley de Daños], http:// www.civillaw.com.cn/qqf/weizhang.asp?id=43175 (última visita el 20 de febrero de 2009).

${ }^{124}$ Zhou Youjun, Lun Wo Guo Guo Cuo Qin Quan De Yi Ban Tiao Kuan [Sobre las disposiciones generales respecto de daños con culpa en el derecho chino], 2007 FA XUE YUE KAN [BOLETÍN MENSUAL DE JURISPRUDENCIA] No 2, en 76; vid. BGB arts. 823, 826, disponible en http:// www.gesetze-iminternet.de/englisch_bgb/. Parágrafo 823 del BGB (Responsabilidad por daños) establece: “(1) Una persona que, intencional o negligentemente, ilícitamente dañe la vida, el cuerpo, la salud, la libertad, la propiedad u otro derecho de otra persona es responsable de compensar a la otra parte por los daños que surjan de esto. (2) El mismo deber pesa sobre la persona que infrinja la ley cuyo propósito es proteger a otra persona. Si, de acuerdo al contenido de la ley, esta puede ser infringida sin culpa, entonces la responsabilidad de compensar solo existirá en el caso de culpa". El parágrafo 826 del BGB (Daño intencional contrario a la política pública) establece: "Una persona que, de un modo contrario a una política pública, intencionalmente inflija daño a otra persona es responsable de reparar el daño".

125 Proyecto de Ley de Daños de octubre de 2008, art. 2 ("Una persona que intencional o negligentemente cause daños es responsable de indemnizar a la otra parte por el daño resultante cuando se violen los siguientes derechos civiles o intereses: (1) los derechos de la personalidad como el derecho a la vida, a la salud, a tener un nombre, a la propia imagen, a la privacidad; (2) las relaciones jurídicas personales como el derecho a la custodia, el derecho de alimentos; (3) el dominio, ius in re aliena, el derecho de garantía del cumplimiento de las obligaciones; (4) los derechos de propiedad intelectual, como el copyright, las patentes, las marcas; (5) otro tipo de derechos civiles e intereses").

126 PGDC art. 106(2) (adoptado por el Comité Permanente Congreso Popular Nacional Chino, 12 de abril de 1986, efectivo el 1 de enero de 1987) LAWINFOCHINA (última visita el 30 de enero de 2009). El artículo 106(2) de los PGDC dispone que: "Los ciudadanos y personas jurídicas que por su culpa usurpen propiedad estatal o colectiva, o la propiedad de otra u otras personas serán civilmente responsables. La responsabilidad civil será soportada incluso en la ausencia de culpa, si la ley así lo dispone". 
nizar los daños resultantes ${ }^{127}$. Además de esta cláusula general, la Ley de Daños china debiere reconocer la "responsabilidad sin culpa" como un caso excepcional frente a la "responsabilidad por culpa", estableciendo que cuando la ley disponga un supuesto típico de responsabilidad sin culpa respecto de una persona, esta será responsable del daño. Este tipo de cláusulas generales (responsabilidad por culpa más responsabilidad sin culpa como una excepción) se basan en los artículos 1382 y 1383 del Código Civil francés ${ }^{128}$, que establecen solo el principio de responsabilidad por culpa. El artículo 7 de la última versión del proyecto de Ley de Daños adoptó esta visión, estableciendo que "aquellos que culpablemente causen daño al cuerpo de otra persona o a su propiedad, serán responsables de este daño". En el caso de que de acuerdo a la ley se presuma la culpa del causante del daño, este será responsable por los daños si no puede probar la falta de culpa. Los opositores a este enfoque critican que las cláusulas generales francesas son anticuadas porque no son aplicables a algunos daños especiales, como aquellos que tienen como consecuencia una responsabilidad objetiva o sin culpa (strict liability) y una responsabilidad por actos de terceros (vicarious liability) ${ }^{129}$. Las cláusulas generales sobre daños en los PGDC son demasiado abstractas como para ser aplicadas correctamente a casos concretos a menos que los jueces estén adecuadamente capacitados. Como la capacitación legal de los jueces chinos de hoy no es garantía suficiente para la aplicación correcta de estas cláusulas generales, parece razonable abandonar este tipo de disposiciones generales. En relación a las cláusulas generales, recientemente cada vez más académicos han aconsejado al legislador aprender del artículo 2027 del Código Civil de Etiopía, de 1960130, y del artículo 1 de los Principios Europeos de Derecho de Daños, del 2005131, los cuales establecen cláusulas

127 Wang Liming, Qing Quan Ze Ren Fa Zhi Ding Zhong De You Guan Wen Ti [Algunos Problemas en la Redacción de la Ley de Daños], 2008 DANG DAI FA XUE [REVISTA DE DERECHO CONTEMPORÁNEO] número 5, en 3; Zhang Xinbao, Qing Quan Xing Wei Fa De Yi Ban Tiao Kuan [Cláusulas Generales de la Ley de Daños], 2004 FA XUE YAN JIU [REVISTA CHINA DE DERECHO] número 1, en 50 .

128 C. C. arts. 1382-1383 (Fr.), disponible en http://www.lexinter.net/ENGLISH/index.htm (seleccionar "Civil Code"). El artículo 1382 del Código Civil francés dispone que, "Cualquier acto del hombre que cause daño a otro, obliga al culpable de su ocurrencia a repararlo". El artículo 1383 del Código Civil francés dispone que, "Toda persona es responsable por el daño que cause no solo intencional, sino también negligentemente o por imprudencia".

129 Zhou Youjun, nota supra 124, en 76.

130 CÓDIGO CIVIL DEL IMPERIO DE ETIOPÍA art. 2027. Este artículo, titulado "Fuentes de la Responsabilidad por Daños", establece:

(1) Independientemente de cualquier garantía o promesa por su parte, la persona será responsable por los daños que cause a otro por un delito. (2) Una persona será responsable, cuando la ley así lo disponga, del daño causado a otro por una actividad en la cual participe o por un objeto que él posea. (3) Una persona será responsable cuando un tercero de quien él es responsable legalmente incurra en responsabilidad resultante de un delito o de la ley.

${ }^{131}$ EUROPEAN GROUP ON TORT LAW, PRINCIPLES OF EUROPEAN TORT LAW: TEXT AND COMMENTARY art. 1:101 (2005) (“(1) La persona a quien se le atribuya legalmente el daño a otro es responsable de compensar ese daño. (2) El daño podrá ser atribuido en particular a la persona: (a) cuya conducta constitutiva de culpa lo haya causado; o (b) cuya actividad anormalmente peligrosa lo haya causado; o (c) cuyos auxiliares o subordinados lo hayan causado dentro del ámbito de sus funciones"). 
generales aplicables a todo tipo de daños ${ }^{132}$. Las cláusulas generales sobre daños del Código Civil francés (arts. 1382 y 1383) no son aplicables a los daños especiales, y aquellas del BGB ( $\$ \$ 823$ y 826) son inaplicables a las acciones que versen sobre daños no pecuniarios. Las cláusulas generales sobre daños, tanto en el Código Civil de Etiopía de 1960 (art. 2027) como en los Principios Europeos de Derecho de Daños del 2005 (art.1) son, en cambio, aplicables a todo tipo de daños; excediendo, por tanto, el alcance de las disposiciones similares del Código Civil francés y del BGB. Además, enumerando algunos tipos especiales de daños, lo que facilita la aplicación de las cláusulas generales a casos concretos, el Código Civil de Etiopía de 1960 y los Principios Europeos de Derecho de Daños de 2005 conjugan los méritos de las cláusulas generales del Derecho continental, así como también los méritos de las detalladas formulaciones típicas (Typenzwang) de daños del common law. Estos son buenos ejemplos para el legislador chino.

\section{Sobre los daños especiales y sus tipos}

Como mencionábamos anteriormente, el proyecto proporciona doce clases de daños típicos. Sin embargo, la mayoría de los académicos del Derecho Civil piensa que esto no es suficiente y que para la futura Ley de Daños es necesario agregar la siguiente tipificación de daños:

\section{a. El daño ocasionado por el Estado}

China promulgó la Ley sobre Indemnización del Estado en 1994, pero es considerado el peor de los estatutos en cuanto a su implementación. Está programada para ser modificada prontamente, pues para una entidad privada actualmente es difícil, si no imposible, obtener una indemnización judicial del Estado ${ }^{133}$. Siendo naturalmente administrativa, esta ley se concentra en la indemnización de los daños causados por la administración estatal o por actividades judiciales del Estado, no obstante ignora casi por completo las indemnizaciones por daños civiles del Estado. Hasta ahora, en China ninguna entidad privada jamás ha sido indemnizada por el Estado por un daño civil. En este contexto, muchos profesores de Derecho señalan que es apropiado e importante que el legislador introduzca el daño cometido por el Estado como un tipo especial de daño ${ }^{134}$.

\footnotetext{
132 Zhang Xinbao, Qing Quan Li Fa Mo Shi Quan Mian De Yi Ban Tiao Kuan Jia Quan Mian Lie Ju [Modelo Legislativo sobre Responsabilidad por Daños Claúsulas Generales Completas más Enumeración Completa de los Tipos de Daño], 2003 FA XUE JIA [REVISTA DE JURISTAS] número 4, en 30; Yang Lixin, Lun Ai Sai Er Bi Ya Qing Quan Xing Wei Fa Dui Zhong Guo Qing Quan Xing Wei Fa De Yi Yi [Sobre la Importancia de la Ley de Daños de Etiopía para la Ley de Daños de China], 2005 YANG ZHOU DA XUE BAO REN WEN SHE HUI KE XUE BAN [REVISTA DE HUMANIDADES Y CIENCIAS SOCIALES DE LA UNIVERSIDAD DE YANG ZHOU] número 5, en 23.

133 Yuan Ting \& Wang Qi, Guo Jia Pei Chang Fa Bei Zhi Shi Shi Zui Cha Fa Lü [La ley de Indemnización del Estado es Considerada la Peor Ley en Términos de Implementación] (18 de marzo de 2008), http:// news.163.com/08/0318/15/47B0LULH00011SM9.html

134 Jiang Ping, Restrospectiva y Perspectiva, supra nota 39, en 8; Wang Liming, supra nota 127, art. 3.
} 


\section{b. El daño proveniente del abuso de confianza}

En la Ley de Daños ¿cómo debería determinarse la responsabilidad de una persona que realiza actividades amistosas (Gefälligkeit) en favor de alguien (por ejemplo, llevarlo en su automóvil) y le causa daños? Actualmente, la ley china no ha otorgado una solución clara y las decisiones tomadas por los jueces no son uniformes. La opinión doctrinal predominante deduce del Derecho continental, y en particular del Derecho alemán, que una persona que otorga ayuda a otro individuo no será responsable por los daños a menos que le cause daños intencionalmente o con manifiesta negligencia ${ }^{135}$. Sin embargo, el proyecto más reciente ha omitido este tipo de daño especial.

\section{c. El daño resultante de accidentes laborales}

En China, la indemnización de daños debida a lesiones personales sufridas durante el trabajo es cubierta por el seguro laboral. De acuerdo al Reglamento Administrativo Sobre el Seguro de Lesiones Laborales, emitido por el Consejo de Estado el 16 de abril de 2003, la indemnización es calculada de acuerdo al grado de incapacidad causada por el accidente, la cual es evaluada por una comisión especializada en capacidad laboral ${ }^{136}$. Sin embargo, si el trabajador no ha sufrido ninguna lesión personal debido al accidente, o estas no son tan severas como para calificarlo como inválido, o la indemnización del seguro pagado de acuerdo a dicha reglamento administrativo no es suficiente como para cubrir todos los daños que este sufrió, ¿cómo debería ser indemnizado por los daños causados en un accidente laboral? Las leyes chinas modernas no han ofrecido una respuesta clara. Según la communis opinio, el empleador será responsable por los daños que sufran sus empleados mientras estén ejerciendo actividades laborales, inclusive si el empleador no ha sido negligente ${ }^{137}$. Entonces, esta clase de responsabilidad por daño debería ser calificada como un tipo de daño especial, dado que esta regla es distinta a la que se aplica en los daños normales.

\footnotetext{
135 Qiu Lufeng, Lun Qing Yi Xing Wei Ze Ren [Sobre la Responsabilidad en Actividades Amistosas], 2008 NANJING DA XUE XUE BAO. ZHE XUE REN WEN SHE KE BAN [REVISTA DE FILOSOFÍA, HUMANIDADES Y CIENCIAS SOCIALES DE LA UNIVERSIDAD DE NANJING] número 5, en 45. 136 Regulación de Seguros de Lesiones relativas al Trabajo (promulgada por el Consejo de Estado, Apr. 16, 2003, efectiva en Ene. 1, 2004), LAWINFOCHINA (última visita el 30 de enero de 2009).

137 Zhang Xinbao, Gong Shang Bao Xian Pei Chang Qing Qiu Quan Yu Pu Tong Ren Sheng Pei Chang Qing Qiu Quan De Guang Xi [La Relación entre el Derecho a Reclamar el Seguro de Lesión Laboral y el Derecho a Reclamar por el Daño Personal Común], 2007 ZHONG GUO FA XUE [CIENCIA JURÍDICA CHINA] número 2, en 100; Zhang Zhaodong, Gong Shang An Jian Pei Chang Qing Qiu Quan Jing He Wen Ti Yan Jiu [Estudio sobre la Concurrencia entre Seguro de Lesión Laboral y Compensación por Lesión Personal], 2007 HE BEI FA XUE [CIENCIA JURÍDICA DE HE BEI] número 3, en 45; Jia Yuanyuan, Lun Gong Shang Bao Xian Ze Ren Jing He An Zhong Jiang De Mo Shi De Shi Yong [Sobre la Aplicación del Modelo de Acumulación a los Casos sobre Seguro de Lesión Laboral], 2008 GUANG XI ZHENG FA GUANG LI GANG BU XUE YUAN XUE BAO [REVISTA DE ADMINISTRACIÓN DEL INSTITUTO GUANGXI DE POLÍTICA Y DERECHO] número 3, en 28.
} 


\section{d. Daño por interferencia en futuras relaciones contractuales}

De acuerdo con las disposiciones sobre interferencia en futuras relaciones contractuales de la sección 766B de la "American Restatement (Second) of Torts"138" y la institución Alemana de la "positive Forderungsverletzung" (derecho para reclamar daños positivos), algunos profesores de Derecho sugieren que la ley establezca la "interferencia en las relaciones contractuales" como un daño especial ${ }^{139}$. Esta idea es compartida por la mayoría de los profesores de Derecho Civil.

\section{e. El daño cometido por el profesional}

La opinión predominante entre los profesores de Derecho chino es que toda responsabilidad por daño profesional -no solo médica, como lo establece el proyecto de la Ley de Daños- debiere ser determinada por medio de la inversión de la carga de la prueba de la culpa y la aplicación de los llamados criterios de determinación de la "culpa in concreto" y la "culpa in abstracto". Por esta razón, el daño profesional debería calificarse como un daño especial dentro de la Ley de Daños china. Esta es la idea que abraza la mayoría de los profesores de Derecho Civil.

\section{Sobre la Indemnización por Daños}

Las disposiciones de los PGDC de 1986 y del Proyecto de Código Civil de 2002 para la indemnización por daños son muy simples. Sin embargo, aquellas establecidas en la interpretación judicial sobre daños ${ }^{140}$ son muy complicadas y tienen varias contradicciones dentro de ellas. Cómo cuantificar la indemnización de los daños y limitar su alcance ha sido objeto de intensos debates durante la redacción de la Ley de Daños. El desacuerdo principal involucra la indemnización por daños personales. Según indica la Interpretación de la Corte Popular Suprema sobre algunos temas concernientes a la aplicación de la ley de juicios sobre causas de indemnización por daños personales (diciembre 26, 2003), la indemnización por daños personales debe ser cuantificada de acuerdo a la pérdida económica de la víctima del daño. Consecuentemente, en el caso de múltiples muertes causados por el mismo daño, la compensación a los ricos es mayor que la de los pobres. En una palabra, "las vidas humanas tienen distintos precios", lo cual, en la

\footnotetext{
138 Restatement (Second) of Torts $\$ 766 \mathrm{~B}(1979)$.

139 WANG LIMING \& YAN LIXIN, QIN QUAN XING WEI FA [DERECHO DE DAÑOS] 157 (1996); Yan Lixin, Xin Lei Xing Qin Quan Xing Wei Zhi Si: Qin Hai Zhai Quan De Qin Quan Xing Wei [El Cuarto Nuevo Tipo de Daño: Interferencia en Futura Relación Contractual], http:// www.civillaw.com.cn/article/defautl.asp?id=43910 (última visita el 8 de abril de 2009).

${ }^{140}$ Opinión de la Corte Popular Suprema sobre Varios Asuntos Concernientes a la Implementación de los Principios Generales de Derecho Civil (Ene. 26, 1988), LAWINFOCHINA (última visita el 30 de enero de 2009); Interpretación de la Corte Popular Suprema en Varios Asuntos Sobre Juicios de Casos Concernientes al Derecho de Reputación (Julio 14, 1998), LAWINFOCHINA (última visita el 30 de enero de 2009); de la Corte Popular Suprema en Problemas Respecto a la Determinación de la Indemnización en la Responsabilidad por Daños Emocionales (Mar. 8, 2001), LAWINFOCHINA (última visita el 30 de enero de 2009); Interpretación de la Corte Popular Suprema en Algunos Asuntos Concernientes a la Aplicación de la Ley para Juicios sobre Casos de Indemnización por Lesiones Personales(Dic. 26, 2003), LAWINFOCHINA (última visita el 30 de enero de 2009).
} 
opinión pública y en la de algunos profesores de Derecho, es contrario a los principios fundamentales constitucionales y de Derecho Civil, que señalan que "la vida y el derecho de personalidad de cada persona es igual ante la ley" ${ }^{141}$.

Las críticas de la solución dada en 2003 por la Corte Suprema para la indemnización por daños personales son cada vez más severas. Recientemente algunos profesores de Derecho han tratado de resolver este problema introduciendo el concepto de "daño biológico" (danno biologico) del Derecho italiano a la Ley de Daños china ${ }^{142}$. De acuerdo a esta teoría, los daños físicos o psicológicos permanentes, llamados "daños biológicos", son distintos a los daños pecuniarios y no pecuniarios que surgen del mismo hecho. Para personas de la misma edad y sexo que han sufrido el mismo daño biológico, la indemnización recibida debería ser la misma, y calcularse de forma independiente de los daños pecuniarios y no pecuniarios. En principio, la indemnización por los distintos daños biológicos puede ser cuantificada objetivamente de acuerdo a los baremos establecidos para los seguros de vida. En este sentido, todas las vidas son iguales ante la ley.

El otro punto de disputa en relación a los daños personales se refiere a cómo definir los daños emocionales y a cómo indemnizarlos. La legislación China no ha adoptado el concepto de "daños no pecuniarios," pero sí el de "daño emocional," que se refiere al sufrimiento emocional de un individuo causado directa o indirectamente por un daño. Claramente, el "daño emocional" es un tipo de daño no pecuniario, pero no se identifica con este último. La Corte Suprema en 2001 emitió una interpretación judicial ad hoc sobre la indemnización por daños emocionales ${ }^{143}$. De acuerdo a esta interpretación, los "daños emocionales" pueden ser indemnizados si provienen de la infracción de

141 PGDC art. 3 (promulgados por la Congreso Popular Nacional, abril 12, 1986, efectivos enero 1, 1987), LAWINFOCHINA (última visita el 30 de enero de 2009) ("Las partes en las relaciones civiles deben tener igual condición.”); XIAN FA [CONSTITUCIÓN] art. 33 (1982) (P.R.C.) (“Todos los ciudadanos de la República Popular China serán iguales ante la Ley.”).

142 Zhang Lihong, Yi Da Li Fa Shang Sheng Wu Xue Zhi Sun Hai Ji Qi Dui Zhong Guo Qin Quan Xing Wei Fa De Qi Shi [Daño Biológico en el Derecho Italiano y su Utilidad en el Derecho Chino], en QIN QUAN FA GAI GE GUO JI LUN TANG LUN WEN JI [COLECCIÓN DE DOCUMENTOS DEL FORO INTERNACIONAL SOBRE LA REFORMA DEL DERECHO DE DAÑOS (Junio 13-14, 2008, SU ZHOU, CHINA)] 176 (junio 2008). Con respecto al concepto de danno biologico en el Derecho Italiano, el profesor Guido Alpa, uno de los más importantes especialistas italianos en Derecho de Daños, observó que "la definición legal de “danno biologico" identifica el daño con la lesión de la integridad mental y física del individuo -la que puede ser valorada desde el punto de vista de la medicina forensecuya restauración no depende de la capacidad productora de ingresos de la parte lesionada... La lesión es, por lo tanto, considerada per se, en cuanto el hecho causante de daño al interés de salud legalmente protegido, de manera que la expresión danno biologico, subyacente en la formulación legal, se identifica con la expresión (considerada más correcta por los autores) de daño a la salud”. Guido Alpa, Personal Injury; Features of the Italian legal System, en EUROPEAN TORT LAW: EASTERN AND WESTERN PERSPECTIVES 153, 170 (Mauro Bussani ed., 2007); ver también GUIDO ALPA \& VINCENZO ZENO-ZENCOVICH, ITALIAN PRIVATE LAW 160 (2007) (con discusión sobre el danno biologico en el Derecho italiano); BASIL MARKESINIS, MICHAEL COESTER, GUIDO ALPA \& AUGUSTUS ULLSTEIN, COMPENSATION FOR PERSONAL INJURY IN ENGLISH, GERMAN AND ITALIAN LAW 85 (2005).

143 Interpretación de la Corte Popular Suprema sobre los Problemas Concernientes a la Determinación de la Indemnización por Responsabilidad por Lesiones Emocionales (Mar. 8, 2001), LAWINFOCHINA (última visita el 30 de enero de 2009). 
un derecho de la personalidad (inclusive de un derecho de la personalidad de una persona muerta), del daño a un adminículo con un valor de afección personal, en el caso de la separación de un pupilo de quien ejerza su custodia, en el de la destrucción de una relación familiar cercana, tal como la de un padre y su hijo, o en el caso de la muerte de algún familiar cercano ${ }^{144}$. Sin embargo, hay muchas otras causas probables de este dicho "daño emocional". Por ejemplo, puede ser causado por una enfermedad de un familiar cercano debido a un daño. Los profesores de Derecho Civil han criticado la posición de la Corte Suprema en cuanto a que solo los "daños emocionales" establecidos en la interpretación judicial pueden ser indemnizados. Ellos reclaman que cualquier sufrimiento mental causado por un daño debería ser compensado.

Recientemente, otros profesores de Derecho también han alegado que "daños emocionales" no es un término legal, de modo que debería ser remplazado por el concepto de "daños no pecuniarios"; en cuanto resulta imposible cuantificar los daños por sufrimiento mental e indemnizarlos de forma separada de otros tipos de daños, tales como los daños biológicos y los daños pecuniarios. De este modo, ellos sugieren clasificar los daños en tres tipos: daños pecuniarios, daños biológicos y daños no pecuniarios (que incluyen los daños a derechos de la personalidad y el detrimento irreversible o destrucción del afecto de una persona a otra o a una cosa ${ }^{145}$. Aun más, como resultado de la significativa influencia que tiene el common law sobre el Derecho de Daños chino, algunos abogan por la compensación de pérdida económica pura en la futura Ley de Daños ${ }^{146}$.

\section{Sobre los Modos de Extinción de la Responsabilidad por Daños}

El artículo 17 del último proyecto de Ley de Daños establece ocho modos principales para la extinción de la responsabilidad por daños: (1) el cese de la infracción, (2) la eliminación de los obstáculos, (3) la eliminación de los peligros, (4) la devolución de la propiedad, (5) la restauración de la condición original, (6) la compensación por pérdida, (7) eliminación de los efectos negativos y la rehabilitación de la reputación, y (8) ofrecer una disculpa ${ }^{147}$. Al establecer el ofrecimiento de una disculpa como un modo para reparar el daño, el proyecto muestra sus señas de identidad propiamente chinas. Tomando la experiencia dada por el common law, muchos profesores de Derecho afirman que es útil y necesario añadir la pena punitiva y la prescripción intermedia del common law como modos de extinción de la responsabilidad por daños ${ }^{148}$.

\footnotetext{
144 Ibid.

${ }^{145}$ Zhang Lihong, supra nota 142 , en 176.

146 LI HAO, CHUN JING JI SHANG SUN SHI PEI CHANG ZHI DU YANG JIU [ESTUDIOS SOBRE PÉRDIDA ECONÓMICA PURA] 12 (2007); Zhang Xinbao, Lun Chun Jing Ji De Ji Ge Ji Ben Wen Ti [Sobre Algunos Problemas Fundamentales en la Pérdida Económica Pura], 2007 FA XUE ZA ZHI [REVISTA DE CIENCIA JURÍDICA] número 4, en 43; ver, también, PURE ECONOMIC LOSS IN EUROPE (Mauro Bussani \& Vernon Valentine Palmer eds., 2003) (traducido al Chino por Zhang Xiaoyi $\&$ Zhong Hongming en 2005).

1472008 proyecto de Ley de Daños, supra nota 104, art. 17

148 Dong Xiaoming, Lun Zhi Shi Chan Quan Su Song Zhong De Lin Shi Jin Ling [Sobre la Prescripción Intermedia en el Juicio de Propiedad Intelectual], 2008 FA LÜ SHI YONG [DERECHO APLICADO] número 7 , en 34 .
} 
Los debates también abarcan otros temas de la teoría de los daños, tales como la necesidad de calificar la violación de una norma de conducta como un elemento constructivo en la atribución de la responsabilidad por daño, el criterio en la limitación de causa y la determinación de la culpa. Limitado por el alcance de este artículo, no puedo referirme a todos ellos en esta ocasión. De cualquier forma, la futura Ley de Daños china, como todas las otras leyes civiles especiales, se espera que sea una mezcla de la experiencia sobre daños del Derecho continental y del common law.

\section{CONCLUSIÓN}

A modo de conclusión, los conceptos fundamentales y principales del Derecho Civil chino se originan en las tradiciones del Derecho Romano y del Derecho continental moderno, y algunas veces son mezcladas con el pensamiento jurídico tradicional y/o socialista. Las normas actuales del Derecho Civil chino provienen de los PGDC de 1986, como un marco de interpretación para el Derecho Civil; al igual que de varias distintas leyes especiales y de interpretaciones judiciales. Probablemente por su flexibilidad, este modelo legislativo esté empezando a ser una tendencia del Derecho Civil codificado moderno en el mundo. La codificación del Derecho Civil chino está programada por el legislador de la siguiente forma: primero, la promulgación de varias leyes civiles especiales, tales como la Ley de Contratación, la Ley sobre Derechos Reales, Ley de Daños y, eventualmente, una Ley de Derechos de la Personalidad y una Ley Unificada de Propiedad Intelectual; segundo, la revisión de los PGDC y su conversión a la Parte General del Código Civil; y, finalmente, la combinación de la Parte General con las leyes especiales de Derecho Civil. En 2007, China promulgó su Ley sobre Derechos Reales, y actualmente está redactando su Ley de Daños, cuya promulgación se espera para el 2010. En la redacción de los PGDC y de todas las leyes civiles especiales -en particular, la Ley sobre Derechos Reales y la Ley de Daños-, el legislador chino adoptó muchas instituciones legales y conceptos del common law. Como resultado, la influencia del common law se está haciendo cada vez más patente en el Derecho Civil de China, tal como en el Código Civil de Louisiana en Estados Unidos. En realidad, el Derecho Civil chino también se presenta como una mixtura, no solo por la gran difusión de los estudios del common law, sino también por el muy especial e importante papel que juega la interpretación judicial en la actual práctica jurídica. El Derecho Civil chino de hoy está basado en el Derecho Romano y el Pandectenrecht. Sin embargo, al incorporar las experiencias del common law en la redacción del Código Civil, los académicos de Derecho chino y el legislador están tratando de superarlos y construir un nuevo y moderno modelo de codificación en el mundo, en el cual se equilibran todas las tradiciones jurídicas en conjunto. 
